


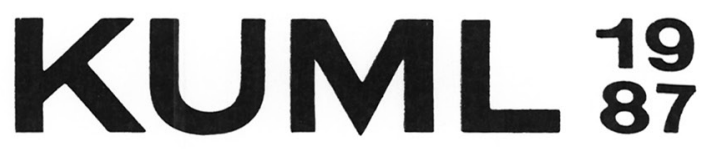

ÅROG FOR
JYSK ARKÆOLOGISK SELSKAB

With Summaries in English

I kommission hos Aarhus Universitetsforlag, Århus 
Omslag:

Rensdyrjagerens våben og bytte.

Udgivet med støtte af Statens humanistiske Forskningsråd

Redaktion: Poul Kjerum

Omslag: Flemming Bau

Tilrettelaggelse: Elsebet Morville

Special-Trykkeriet Viborg a-s

Skrift: Baskerville 11 pkt.

Papir: Stora G-print $120 \mathrm{gr}$.

Copyright 1989 by Jysk Arkeologisk Selskab

ISBN 87-7288-050-3

ISSN 04546245 


\section{Indhold/Contents}

H. Hellmuth Andersen: Udgravningerne i Gammel Lybæk og abodriterkongen Henrik. Træk af en politisk biografi i

arkæologisk belysning

Die Ausgrabungen in Alt Lübeck im Lichte der politischen

Biographie des Abodriten Königs Heinrich

Mytte Fentz: En hørskjorte fra 1000-årenes Viborg ............................................... 23

An 11 th century linen shirt from Viborg ……........................................ 45

Torben Nilsson: Senglacial bosættelse i Vendsyssel .................................................. 47

Late Glacial settlement in Vendsyssel ........................................................... 75

Karsten Kjer Michaelsen: En senneolitisk hustomt fra Vendsyssel ............................... 77

A Late neolithic house-site from Vendsyssel ............................................. 85

Inge Bodilsen: Enkeltfund - votivfund i dansk bronzealder .................................... 87

Single finds - votive finds in the Danish Bronze Age ....................................... 103

Tine Trolle-Lassen: Jernaldergravpladsen ved Vogn.

En arkæologisk-osteologisk undersøgelse ............................................... 105

The Iron Age cemetery of Vogn. An archaeological

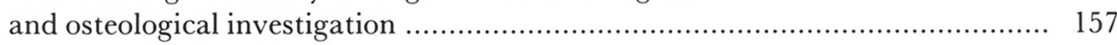

Jysk Arkeologisk Selskab 1987 .................................................................. 164 


\title{
Senglacial bosættelse i Vendsyssel
}

\author{
Af Torben Nilsson
}

Da Therkel Mathiassen i 1946 skrev sin artikel om bopladsen ved Bromme, gjorde han samtidig status over det øvrige danske senglaciale fundstof (1). Fra Vendsyssel omtaltes dengang seks enkeltfundne senglaciale redskaber fordelt på fem fundlokaliteter - et fundbillede, der frem til i dag, stort set har fået lov til at stå uændret i litteraturen.

Siden 1946, men specielt inden for det sidste årti, er der imidlertid sket en drastisk ændring af Vendsyssels senglaciale fundbillede. Antallet af fundlokaliteter er forøget til $25 \mathrm{og}$ de første bopladser er dukket op (2).

I den foreliggende artikel gøres der status over Vendsyssels (3) senglaciale fundstof anno 1989, men hovedvægten vil blive lagt på præsentationen af et større aktivitetsområde, Hollendskær, der omfatter 13 tætliggende bopladser.

Da hele Vendsyssels senglaciale fundstof består af rekognosceringsfund, vil der i fundfremlæggelsen hovedsageligt kun blive medtaget redskaber, der ud fra form og fremstillingsteknik klart kan henføres til det senglaciale fundstof.

Fundlokaliteterne vil i den følgende fremlæggelse optræde enten som enkeltfund eller som bopladser. Ved enkeltfund skal forstås fund af et enkelt isoleret liggende typedefineret senglacialt redskab. Ved boplads skal forstås tilstedeværelse af mindst et typedefineret senglacialt redskab i selskab med en eller flere genstande, der med større eller mindre sikkerhed kan henføres til det senglaciale fundstof. Betegnelsen aktivitetsområde anvendes, hvor flere enkeltfund og/eller bopladser ligger i umiddelbar nærhed af hinanden.

\section{Enkeltfund}

Allerede for 100 år siden, da Vendsyssel historiske Museum i 1889 blev oprettet, indførtes, som protokolnr. 12, det første senglaciale enkeltfund, en skafttungespids (fig. 2 nr. 1), i museets protokoller. Det samlede antal enkeltfund fra Vendsyssel er siden nået op på 12.

Enkeltfundene består af 10 skafttungespidser (fig. 2 og 3), samt to slagvåben af rentak, begge fra Nørre Lyngby, Lyngby sn. (NM nr. A 16678 og VHM nr. 1975/73). 


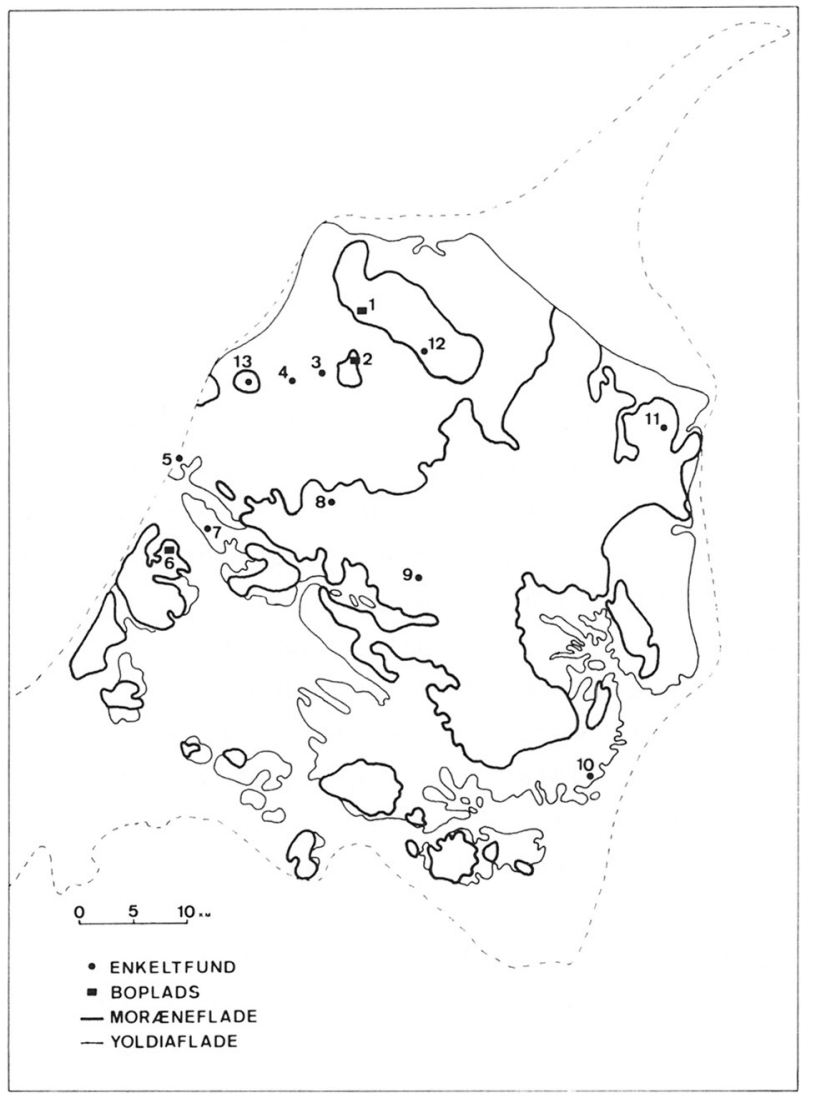

Fig. 1. Senglaciale fundlokaliteter i Vendsyssel: 1, Hollendskær (Varbro I-IV og Ramsgård I-IX). 2, Højvælde. 3, Frydslund. 4, Villerup. 5, Nr. Lyngby. 6, Trudslev. 7, Vrensted sogn. 8, Vrå sogn. 9, Jerslev sogn. 10, Aså-Melholt sogn. 11, Flade sogn. 12, Astrup sogn. 13, Vennebjerg sogn. Placeringen af udbredelseskortets lokaliteter 7-13 skal tages med forbehold, da præcise fundstedsoplysninger mangler for disse lokaliteter.

Late Glacial discovery sites in Vendsyssel. 1: Holledskær (Varbro I-IV and Ramsgård I-IX), 2: Højvælde, 3: Frydslund, 4: Villerup, 5: Nørre Lyngby, 6: Trudslev, 7: Vrensted parish, 8: Vrå parish, 9: Jerslev parish, 10: Aså-Melholt parish, 11: Flade parish, 12: Astrup parish, 13: Vennebjerg parish. The placing of sites 7-13 on the diffusion map should be accepted with reservation, as precise information concerning place of discovery is not available for these localities.

De senglaciale enkeltfund fra Vendsyssel er alle fundet på højtliggende moræne- eller yoldiaflader (fig. 1).

Enkeltfundene, på nær skafttungespidsen og de to rentakslagvåben fra Nørre Lyngby, er som rekognosceringsfund fundet i pløjejord og kan derfor ikke forbindes til forhistoriske anlæg eller bestemte geologiske lag. Skafttungespidsen fra Nørre Lyngby (fig. 3 nr. 1), der fremkom i senglaciale ferskvandsaflejringer i en søprofil i kystskrænten (4), er fundet i lag, der pollenanalytisk kan dateres til begyndelsen af yngre dryas, pollenzone III, - men skafttungespidsen må karakteriseres som værende af Bromme-type.

Også de øvrige enkeltfundne skafttungespidser kan, trods stor formmæssig variation, karakteriseres som skafttungespidser af Bromme-type. Skafttungespidserne er gennemgående grove og kraftige i deres udformning og overvejende fremstillet af »højryggede« flækker med trekantet tværsnit. Flækkerne er frembragt ved hårdt direkte slag, og hovedparten af skafttungespidserne har kraftigt markeret slagbule bevaret. Slagfladeresten, på de skafttungespidser der har dele af den oprindelige slagflade bevaret (fig. 2 nr. 1-5 samt fig. 3 nr. 1, 3 og 4), fremstår med en vinkel på over 90 grader 
set i forhold til bugsidens længdegående forløb. Skafttungens tilhuggede sidekanter, der i alle tilfælde er tilhugget fra flækkernes bugsider, forløber tilnærmelsesvis parallelt på otte af skafttungespidserne (fig. 2 nr. 1, 35 og 6
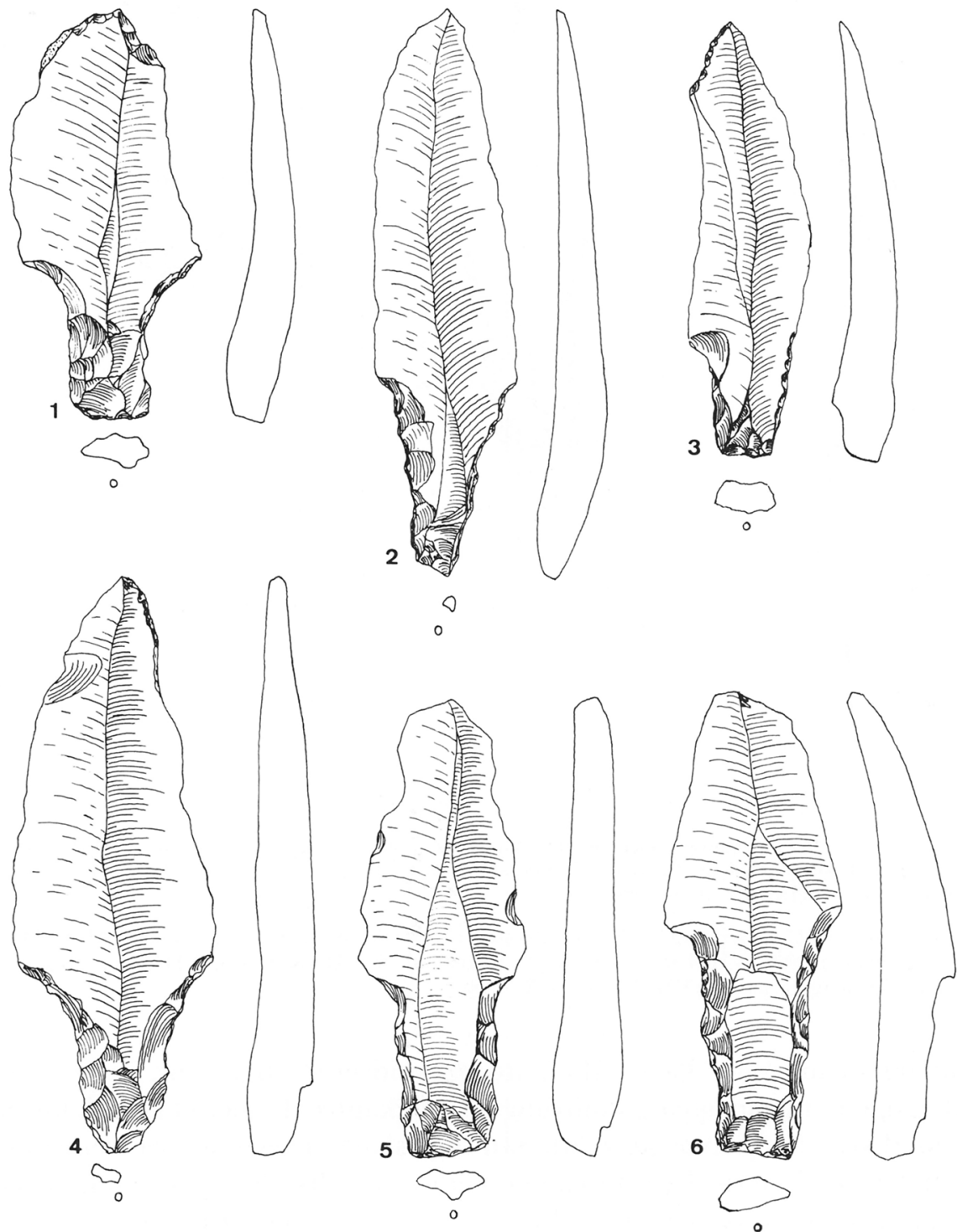

Fig. 2. Enkeltfundne skafttungespidser fra Vendsyssel. 1. Vennebjerg sn, (VHM nr. 12), 2: Flade sn. (VHM nr. 1081), 3: Aastrup sn. (VHM nr. 3487), 4: Jerslev sn. (VHM nr. 3978), 5: Vrensted sn. (VHM nr. 13339), 6: Vrå sn. (VHM nr. 22630).

Single discoveries of tanged points from Vendsyssel. 1: Vennebjerg parish (VHM no. 3487), 4: Jerslev parish (VHM no. 3978), 5: Vrensted parish (VHM no. 13339), 6: Vrå parish (VHMno. 22630). 

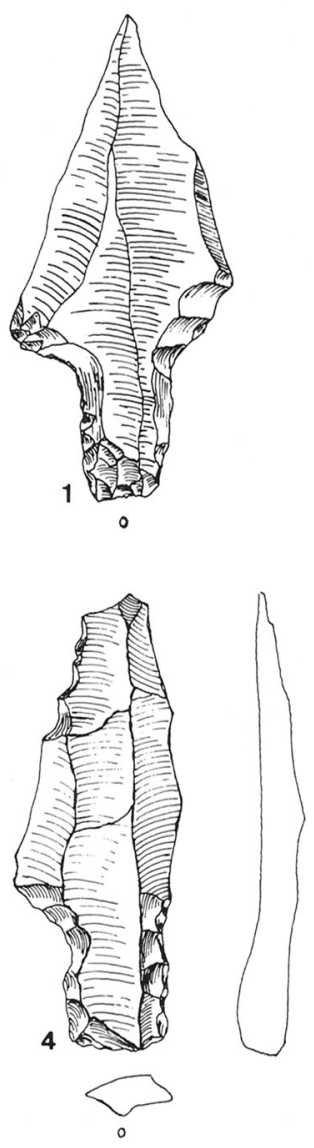

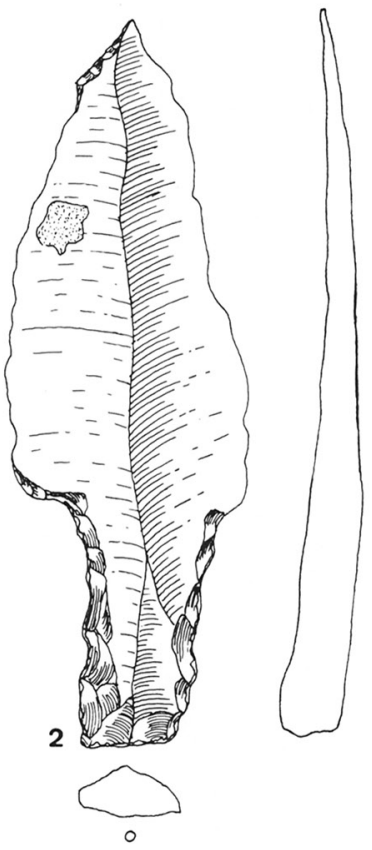

Fig. 3. Enkeltfundne skafttungespidser fra Vendsyssel. 1: Nørre Lyngby, Lyngby sn. (NM A 31405), 2: Aså-Melholt sn. (VHM nr. 1941/96), 3: Frydslund, Sct. Hans sn. (VHM nr. 1976/1, 4: Villerup, Vennebjerg sn. (VHM sag nr. 81/1989).

Single discoveries of tanged points from Vendsyssel. 1: Nørre Lyngby, Lyngby parish (NM A 31405), 2: Aså-Melholt parish (VHM no. 1941/96), 3: Frydslund, Sct. Hans parish (VHM no. 1976/1), 4: Villerup, Vennebjerg parish (VHM case no. 81/1989).

samt fig. 3 nr. 1-4). På to af skafttungespidserne (fig. 2 nr. 2 og 4) er skafttungen »tilspidset« og skafttungens sidekanter danner et konisk forløb ind mod skafttungespidsens blad. Samtlige skafttungespidser er fremstillet af flækker med »naturligt« forekommende spids distalende, der udgør odden på de færdige skafttungespidser. På skafttungespidserne (fig. 2 nr. 3 og 4 samt fig. 3 nr. 2-4) er der foretaget ensidet retouchering af odden. Skafttungespidsen (fig. 2 nr. 1) har dobbeltsidet retouchering af odden. Skafttungespidserne varierer i længde fra 6,2-9,8 cm og i bredde fra 1,9-3,2 cm.

De to slagvåben af rentak er begge fundet på stranden ved Nørre Lyngby, tæt ved søprofilen hvor skafttungespidsen blev fundet. Det er således 
sandsynligt, at slagvåbnene begge er udvasket af senglaciale ferskvandsaflejringer i søprofilen. Det ene slagvåben, der blev fundet i slutningen af 1800-tallet, er fremstillet af rentak. Det er ca. $48 \mathrm{~cm}$ langt og har lige afskåret, let udhulet sidegren. Det andet slagvåben, der blev fundet i 1974, er sandsynligvis fremstillet af rentak, men kan være fremstillet af kronhjortetak (5). Slagvåbnet er $39 \mathrm{~cm}$ langt, men brudflader i slagvåbnets "basisende" gør det sandsynligt, at det har været længere end de $39 \mathrm{~cm}$. Slagvåbnet har skråt afskåret sidegren.

Fra det øvrige Danmark kendes yderligere otte rentakslagvåben (6). Typemæssigt kan de to slagvåben fra Nørre Lyngby henføres til Ahrensburgkulturens gruppe af slagvåben, men da rentakslagvåben fra Danmark endnu ikke er fundet i daterbar kontekst, kan de ikke med sikkerhed kronologisk tilknyttes Ahrensburgkulturen.

\section{Bopladser}

I Vendsyssel kendes ialt 15 senglaciale bopladser (fig. 1), der alle er fundet inden for de sidste 6 år. To af bopladserne, Trudslev og Højvælde, ligger alene, medens de øvrige 13 boplader, Varbro I-IV og Ramsgård I-IX, er beliggende indenfor eet større aktivitetsområde, Hollendskær.

Trudslev, Ingstrup sogn. VHM sag nr. 153/1988. Bopladsen er beliggende på en sandet morænebakke ca. $23 \mathrm{~m}$ over DNN. Umiddelbart nord og øst for morænebakken lå tidligere meget store vådområder.

Genstandsmaterialet, der er fundet på flad mark inden for et ca. $5 \times 5 \mathrm{~m}$ stort areal, omfatter 1 fragmenteret skafttungespids (fig. 4 nr. 1), 2 stikler (fig. 4 nr. 2-3), enkelte grove flækker samt ildskørnet flint. Skafttungespidsen, der er brækket ved skafttungens overgang til bladet, er af kraftig bredbladet type. Skafttungen har slagbule samt dele af slagfladeresten bevaret.

Stiklerne, en kant- og en tværstikkel, er fremstillet af små grove uregelmæssige skiver. På kantstiklen (fig. 4 nr. 2) er stikkelslaget udført på brud. Tværstiklen (fig. 4 nr. 3) har flere tværslag på skivens spidse distalende.

Genstandsinventaret fra Trudslev-bopladsen kan, på grundlag af skafttungespidsen, henføres til Brommekulturen.

Højvalde, Hjørring sogn, VHM sag nr. 295/1987. Bopladsen (8) er beliggende på en større terrasse på nordsiden af en sandet morænebakke ca. 37 $\mathrm{m}$ over DNN. Umiddelbart nord for pladsen ligger der et mindre vådområde med forbindelse til Liver å.

Redskabsinventaret, (fig. 4 nr. 4-6), der er fundet inden for et ca. $50 \times$ $30 \mathrm{~m}$ stort område, omfatter 2 skafttungespidser og en skiveskraber. Skafttungespidserne, der har groft tilhuggede sidekanter, har slagbule og slagfladerest bevaret. Skafttungespidsen (fig. 4 nr. 4) er fremstillet af et groft 

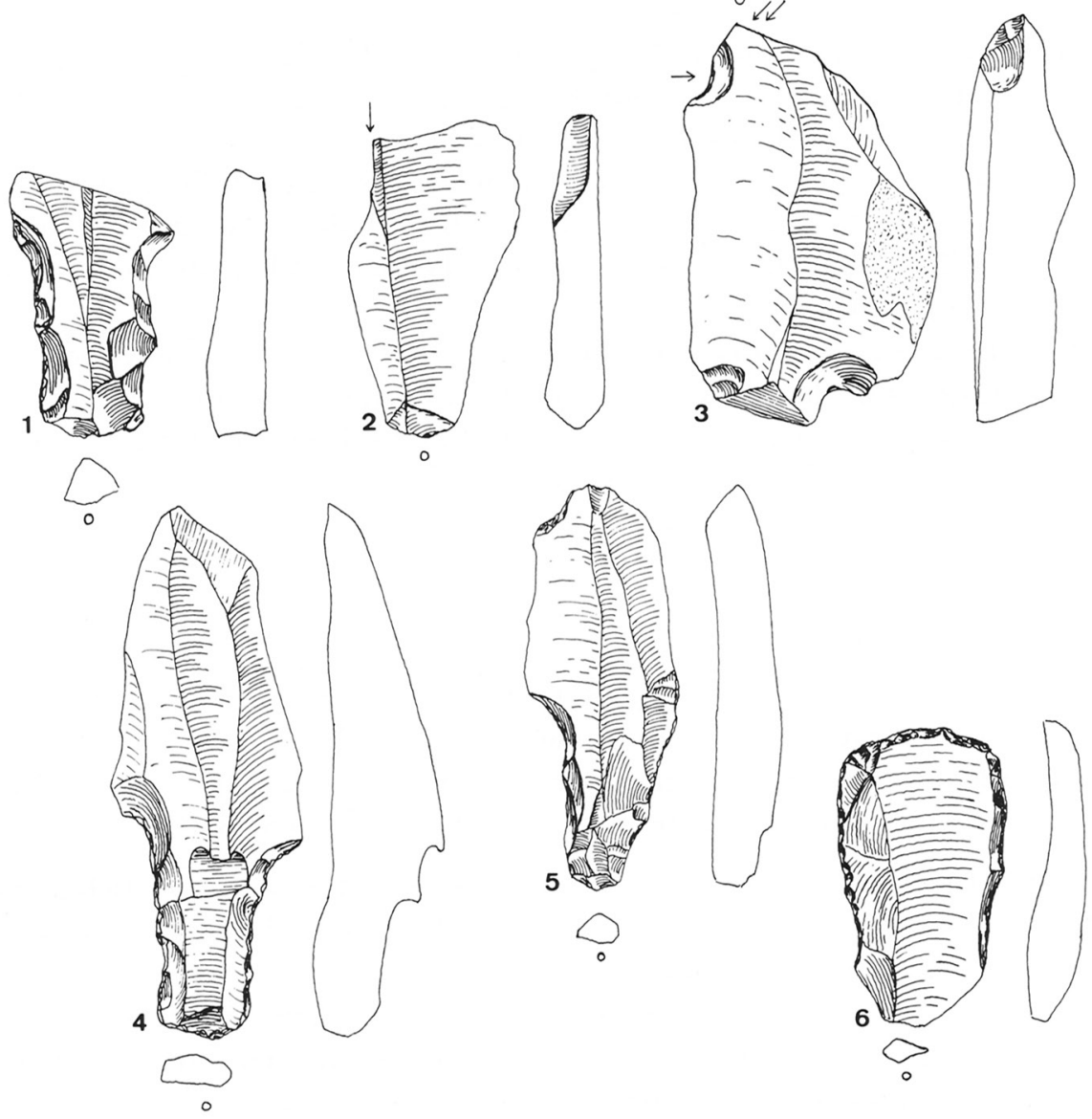

Fig. 4. Flintredskaber fra bopladserne Trudslev, nr. 1-3, samt Højvælde, nr. 4-6. 3:4.

Flint implements from settlements Trudslev, nos. 1-3, and Højvælde, nos. 4-6. 3:4.

»højrygget « bloksideafslag. Skiveskraberen (fig. 4 nr. 6) har retoucherede længdekanter og stejlretoucheret ægforløb.

Skafttungespidserne kan, ud fra deres form og fremstillingsteknik, henføres til Brommekulturen, men paralleler til skiveskraberen kendes både fra Bromme (9), Jels I (10), Løvenholm (11) samt fra Federmessergruppens bopladsfund (22).

\section{Hollendskær}

Aktivitetsområdet Hollendskær (7), der omfatter 13 bopladser, strækker sig over et ca. $200 \times 700 \mathrm{~m}$ stort område beliggende omkring et større engdrag (fig. 5). Engdraget, der er omgivet af høje sandede morænebakker, 


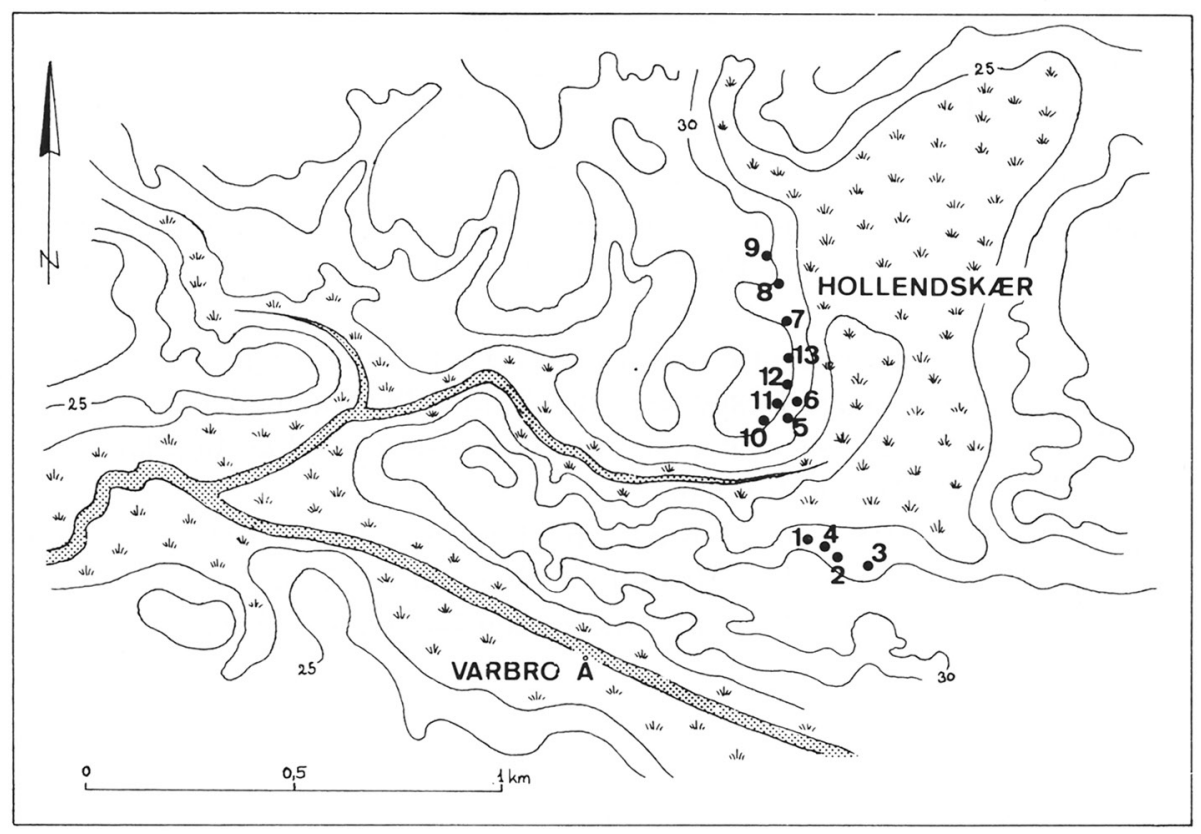

Fig. 5. Aktivitetsområdet Hollendskær. 1-4, Varbro I-IV. 5-13, Ramsgård I-IX.

Activity area Hollendskær. 1-4: Varbro I-IV. 5-13: Ramsgård I-IX.

udgjorde i senistiden en ca. $0,5 \mathrm{~km}^{2}$ stor ferskvandssø. Søen havde via en smal kløft forbindelse til en større ådal, der i dag gennemskæres af Varbro å. Bopladserne er beliggende højt i morænebakkerne ved syd- og vestbredden af engdraget på begge sider af afvandingskløften.

Varbro I, Bjergby sogn. VHM sag nr. 155/1988. Bopladsen, der udgør et ca. $15 \times 15 \mathrm{~m}$ stort areal, er beliggende ca. $27,5 \mathrm{~m}$ over DNN på nordvendt let skrånende terræn (fig. 5).

Bopladsens redskabsinventar (fig. 6) består af 5 skafttungespidser (fig. 6 nr. 1-5) og 1 skiveskraber (fig. 6 nr. 6). Desuden er der fundet 31 forarbejdede og uforarbejdede flækker og skiver, der med større eller mindre sikkerhed kan medregnes til det senglaciale genstandsinventar.

Skafttungespidserne, hvoraf de 4 er fragmenterede, varierer i form og størrelse, men fremstillingsteknisk er de ens. Skafttungespidserne, der er fremstillet af grove uensartede flækker, har i fire tilfælde dele af den oprindelige slagflade bevaret. Råemnet, flækkerne, er fremstillet ved hårdt direkte slag. Tilhugningen af skafttungerne, der på alle 5 skafttungespidser har tilnærmelsesvis parallelt løbende sidekanter, er foretaget fra flækkernes bugsider. Skafttungespidsen (fig. 6 nr. 2) er, sandsynligvis efter en beskadigelse af odden, genanvendt som stikkel. Den fragmenterede skafttungespids (fig. $6 \mathrm{nr}$. 3) er genanvendt som skraber. 
Skiveskraberen (fig. 6 nr. 6) samt de 5 skafttungespidser kan ud fra form og fremstillingsteknik placeres tæt op ad lignende redskabstyper fra Bromme (1) samt Bro (12).

Varbro II, Bjergby sogn. VHM sag nr. 151/1988. Bopladsens redskabsinventar er opsamlet indenfor et ca. $20 \times 20 \mathrm{~m}$ stort areal. Bopladsen er beliggende ca. 27,5 m over DNN på nordvendt let skrånende terræn (fig. $5)$.

Bopladsens redskabsinventar (fig. 7) består af 1 skafttungespids, 2 skiveskrabere og 1 flækkekniv. Desuden er der fundet 28 forarbejdede og uforarbejdede flækker og skiver, der med større eller mindre sikkerhed kan medregnes til det senglaciale fundstof.

Skiveskraberen (fig. $7 \mathrm{nr}$. 2), med snudeformet ægforløb, kendes i lignende eksemplarer fra Bro (13), Bromme (14) samt fra Langå I (15). Skiveskraberen (fig. 7 nr. 3), der i proximalenden har en kort bred skafttunge,
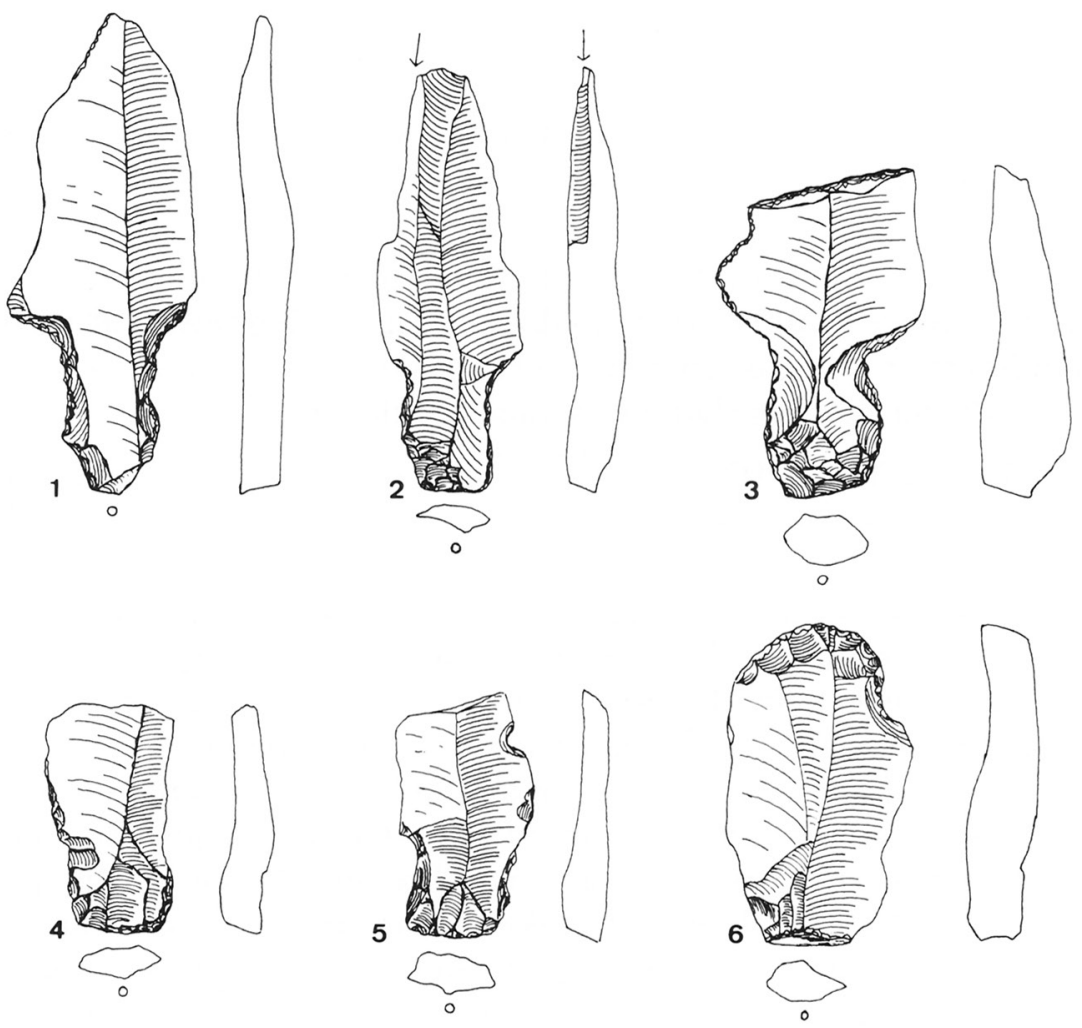

Fig. 6. Skafttungespidser og skraber fra bopladsen Varbro I. 3:4.

Tanged points and scraper from settlement Varbro I. 3:4. 

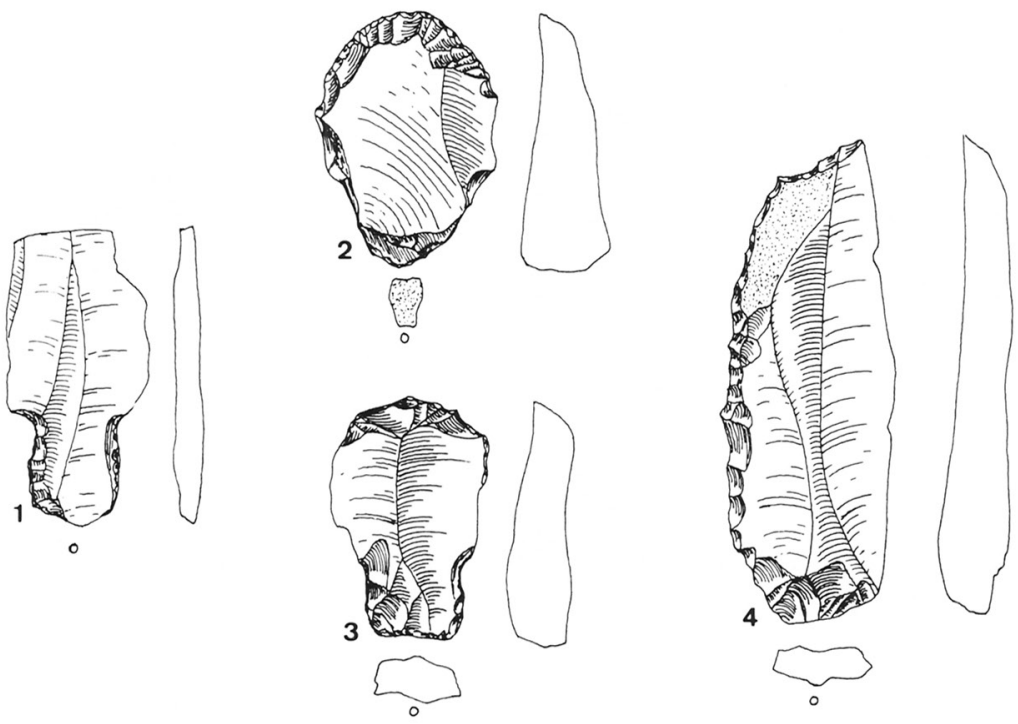

Fig. 7. Skafttungespids, skrabere og flækkekniv fra bopladsen Varbro II. 3:4.

Tanged point, scrapers and blade knife from settlement Varbro II. 3:4.

kan være fremstillet af en brækket skafttungespids. Begge skiveskrabere har fladretoucherede ægforløb.

Den »rygretoucherede« flækkekniv med let afsat spidsretouche kendes ikke i andre tilfælde fra Brommekulturens bopladsfund, men indenfor Federmessergruppens genstandsinventar (16) er redskabsformen forekommende i forskellige varianter.

Varbro III, Bjergby sogn. VHM sag nr. 157/1988. Bopladsen er beliggende ca. 27,5 m over DNN på nordvendt skrånende terræn (fig. 5). Bopladsens genstandsinventar fandtes indenfor et ca. $15 \times 15 \mathrm{~m}$ stort areal.

Redskabsinventaret (fig. 8) består af 1 skafttungespids, 4 skiveskrabere og 1 stikkel. Desuden er der fundet 27 forarbejdede og uforarbejdede flækker og skiver, der med større eller mindre sikkerhed kan medregnes til det senglaciale fundstof.

Skafttungespidsen har lang og groft tilhugget samt tilspidset skafttunge, hvor slagfladeresten er borthugget ved skafttungens tilspidsning. Samme type skafttungespids kendes fra Bromme (17).

Skiveskraberen (fig. $8 \mathrm{nr}$. 5) har let afsat skulder og fladretoucheret ægforløb. De øvrige skiveskrabere har rundbuet ægforløb og mere stejl ægretouche. 3 af skiveskraberne (fig. 8 nr. 2, 3 og 5) er ildskørnede. 

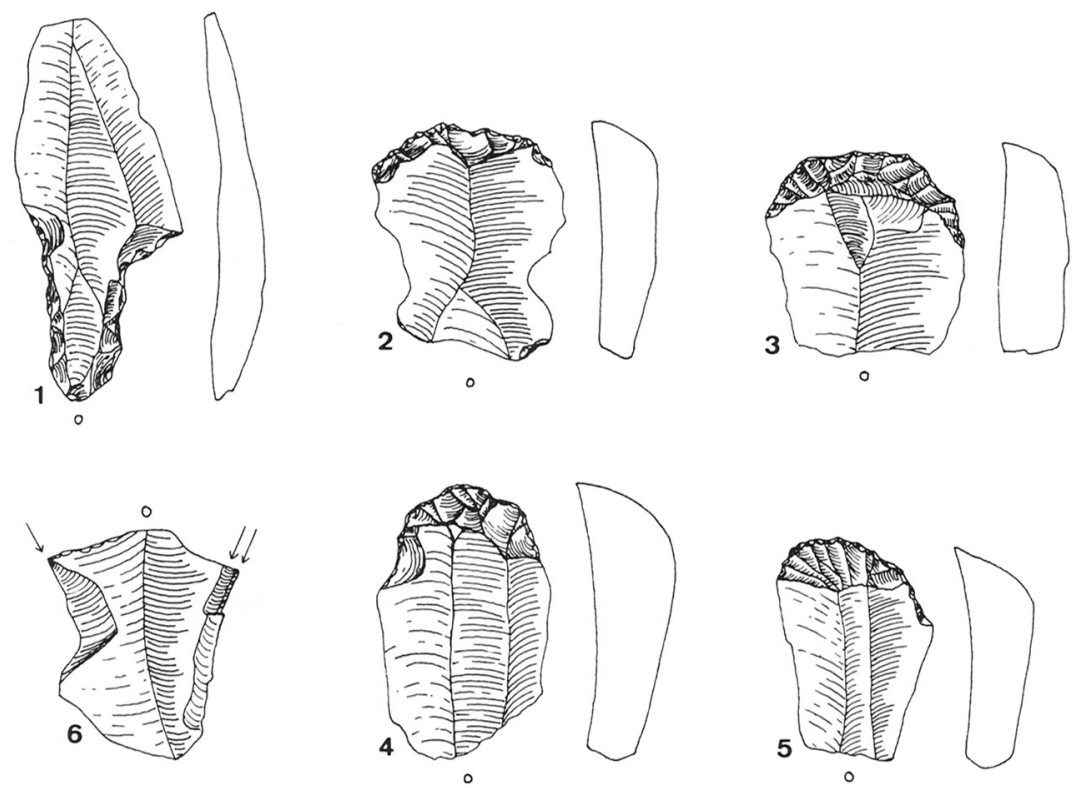

Fig. 8. Skafttungespids, skrabere og stikkel fra bopladsen Varbro III. 3:4.

Tanged point, scrapers and burin from settlement Varbro III. 3:4.

Varbro IV, Bjergby sogn. VHM sag nr. 158/1988. Bopladsen er beliggende ca. 27,5 m over DNN på nordvendt skrånende terræn (fig. 5). Pladsens redskabsinventar (fig. 9), der fandtes indenfor et ca. $20 \times 15 \mathrm{~m}$ stort areal, består af 3 skafttungespidser, 1 flækkekniv og 1 flækkeskraber. Desuden er der fundet 23 forarbejdede og uforarbejdede flækker og skiver, der med større eller mindre sikkerhed kan henføres til det senglaciale fundstof.

De 3 skafttungespidser (fig. 9 nr. 1-3) er vidt forskellige af form og størrelse, men fremstillingsteknisk set er de ens. Skafttungespidsen (fig. 9 nr. 1) er usædvanlig stor i sammenligning med de øvrige skafttungespidser fra aktivitetsområdet Hollendskær. Bopladsens skafttungespidser kan kategoriseres som skafttungespidser af Bromme-type.

Flækkekniven (fig. 9 nr. 4) ligger typemæssigt tæt op ad flækkekniven fra Varbro II (fig. 7 nr. 4).

Flækkeskraberen (fig. $9 \mathrm{nr}$. 5) kendes i lignende eksemplarer fra Bro (18), Langå I (15) og Bromme (19).

Ramsgård I, Bjergby sogn. VHM sag nr. 285/1986. Bopladsen, der udgør et ca. $25 \times 15 \mathrm{~m}$ stort areal, er beliggende ca. $28 \mathrm{~m}$ over DNN på let mod syd og øst hældende terræn (fig. 5).

I 1987 gennemførte Vendsyssel historiske Museum en prøvegravning på lokaliteten uden at finde senglacialt genstandsmateriale under pløjelagsdybde. 

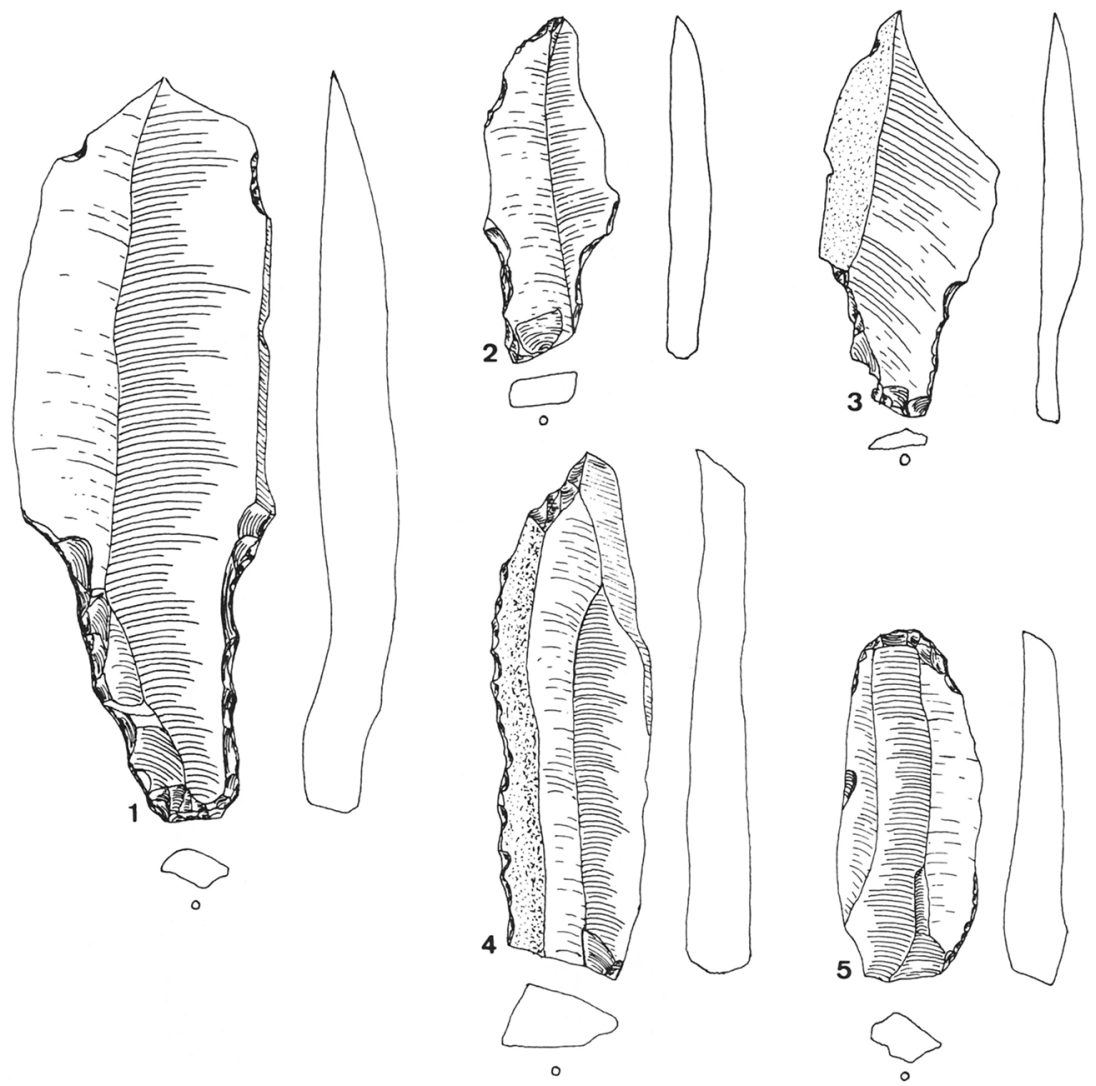

Fig. 9. Skafttungespids, skraber og flækkekniv fra bopladsen Varbro IV. 3:4.

Tanged points, scraper and blade knife from settlement Varbro IV. 3:4.

Bopladsens redskabsinventar (fig. 10-11) består af 10 skafttungespidser, 6 skrabere og 5 stikler. Desuden er der fundet 53 forarbejdede og uforarbejdede flækker og skiver, der med større eller mindre sikkerhed kan medregnes til det senglaciale fundstof.

Skafttungespidserne er formmæssigt forskellige og varierer fra 4,9-7 cm i længden og fra 1,5-2,5 i bredden. Skafttungespidserne fig. $10 \mathrm{nr}$. 1, 3, 5, 6 og 8-10 har groft tilhuggede og tydeligt markerede skafttunger, hvorimod skafttungespidserne fig. $10 \mathrm{nr} .2 \mathrm{og} 4$ har fint tilhuggede og svagt markerede skafttunger. Ensidet retouchering af odden er foretaget på skafttungespidserne (fig. $10 \mathrm{nr}$ 1, 4 og 6). I 5 tilfælde foreligger skafttungespidserne som fragmenter. Spidsfragmentet fig. 10 nr. 7, der er brækket af lige over skafttungens overgang til bladet, viser samtidig svær lædering af odden. På tre skafttungefragmenter (fig. $10 \mathrm{nr}$. 8-10) er skafttungen afbrækket lige ved overgangen til bladet. 

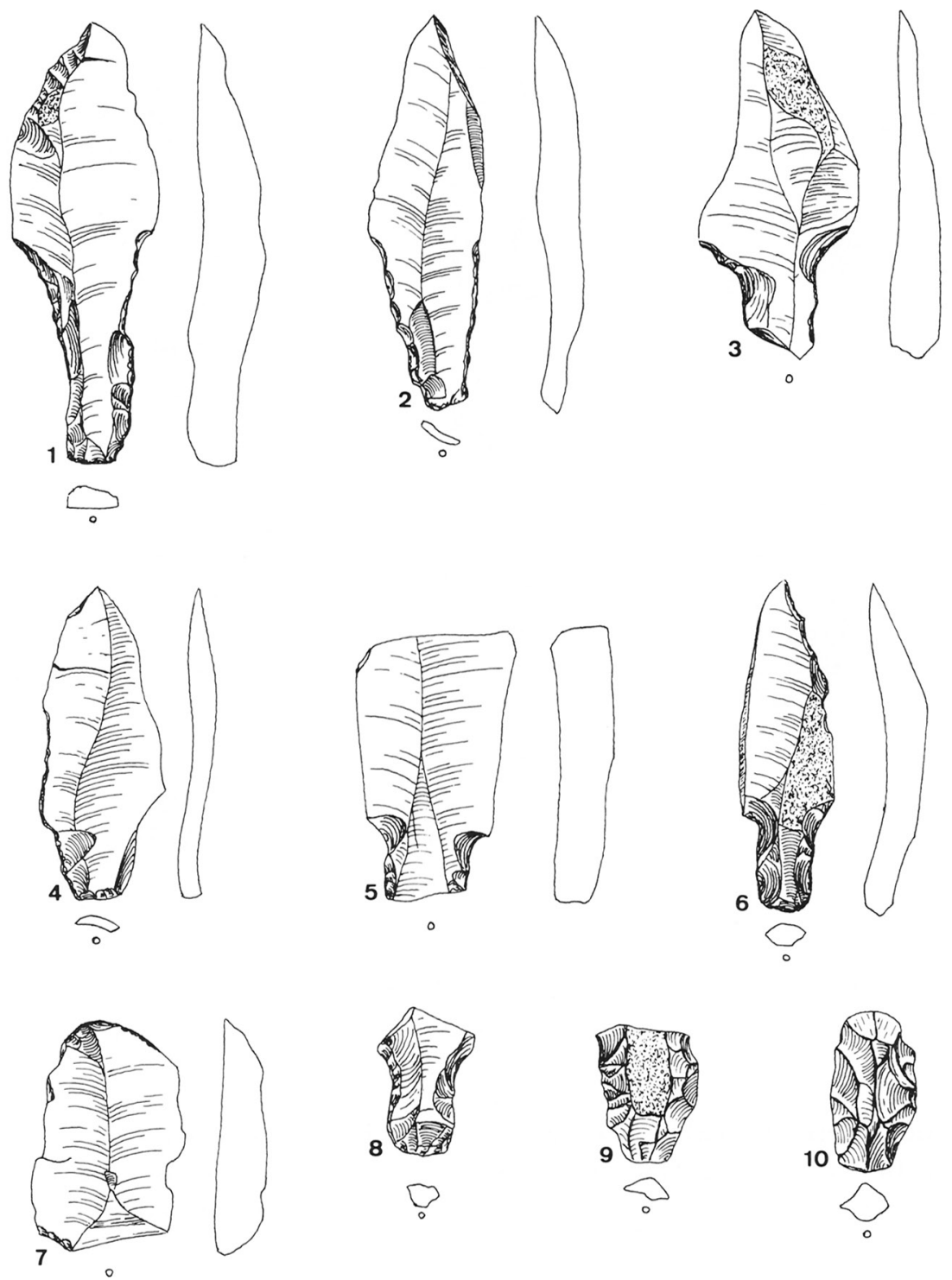

Fig. 10. Skafttungespidser fra bopladsen Ramsgård I. 3:4.

Tanged points from settlement Ramsgård I. 3:4.

De 6 skiveskrabere (fig. $11 \mathrm{nr}$. 1-6), der alle har fladretoucherede ægforløb, er gennemgående små, men ellers af typemæssig stor variation. Skiveskraberne (fig. $11 \mathrm{nr}$. 2, 3 og 6) findes i lignende eksemplarer fra »klassisk « Brommeinventar. Skiveskraberen (fig. 11 nr. 5) har tildannet skafttunge og kan være en genbrugt brækket skafttungespids. De to skiveskrabere (fig. 11 

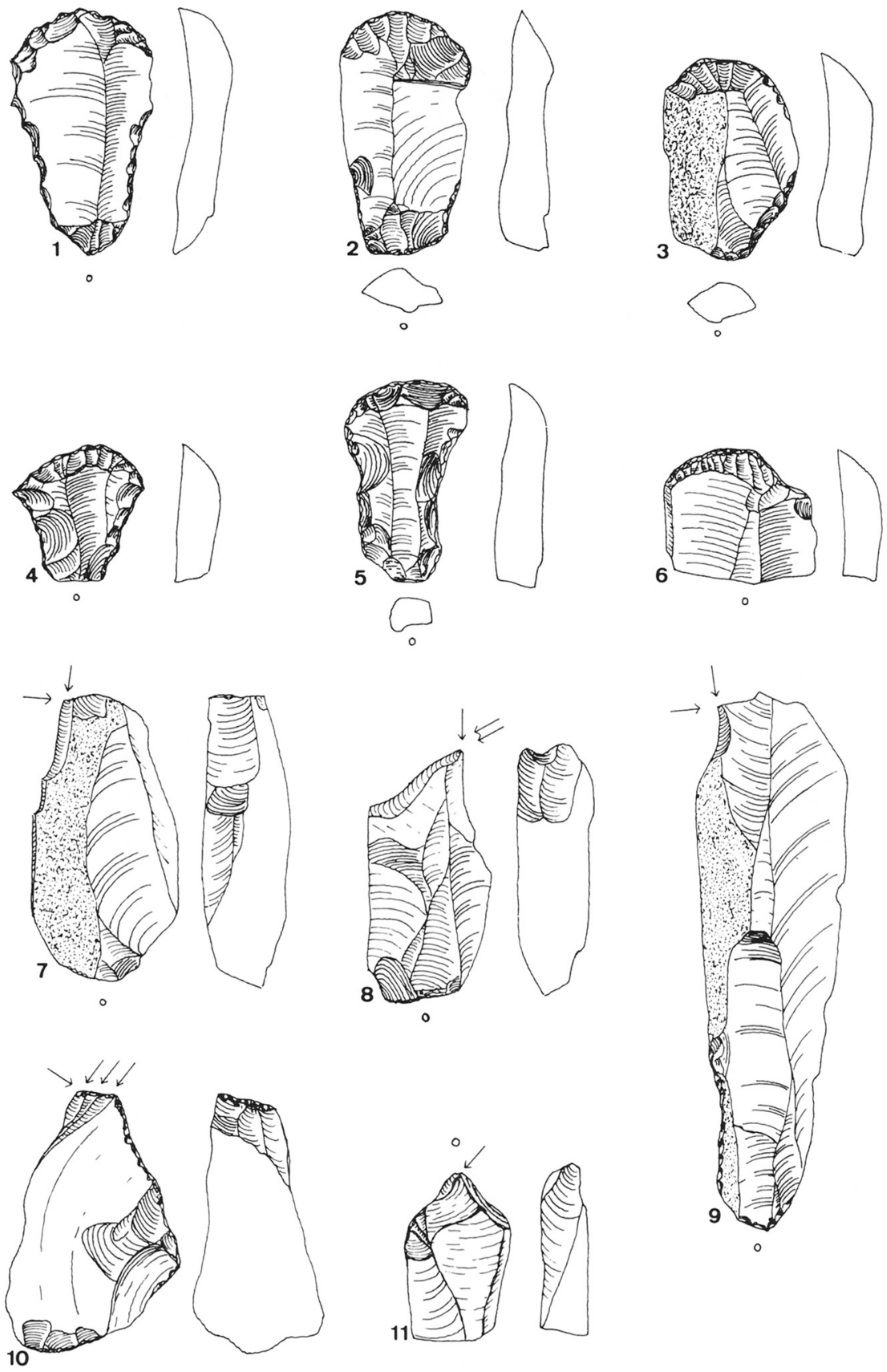

Fig. 11. Skrabere og stikler fra bopladsen Ramsgård I. 3:4.

Scrapers and burins from settlement Ramsgård I. 3:4. 

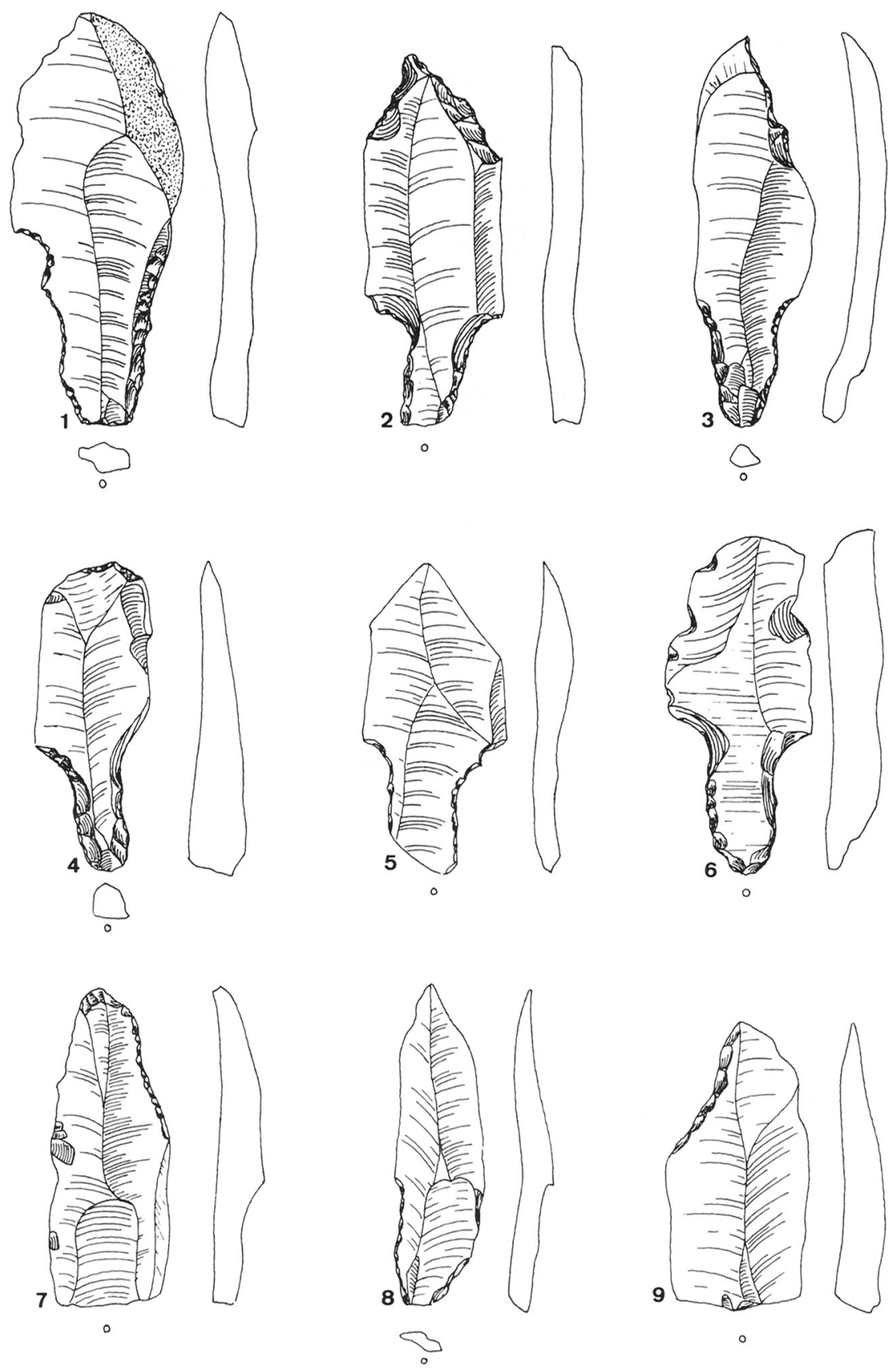

Fig. 12. Skafttungespidser fra bopladsen Ramsgård II. 3:4.

Tanged points from settlement Ramsgård II. 3:4. 

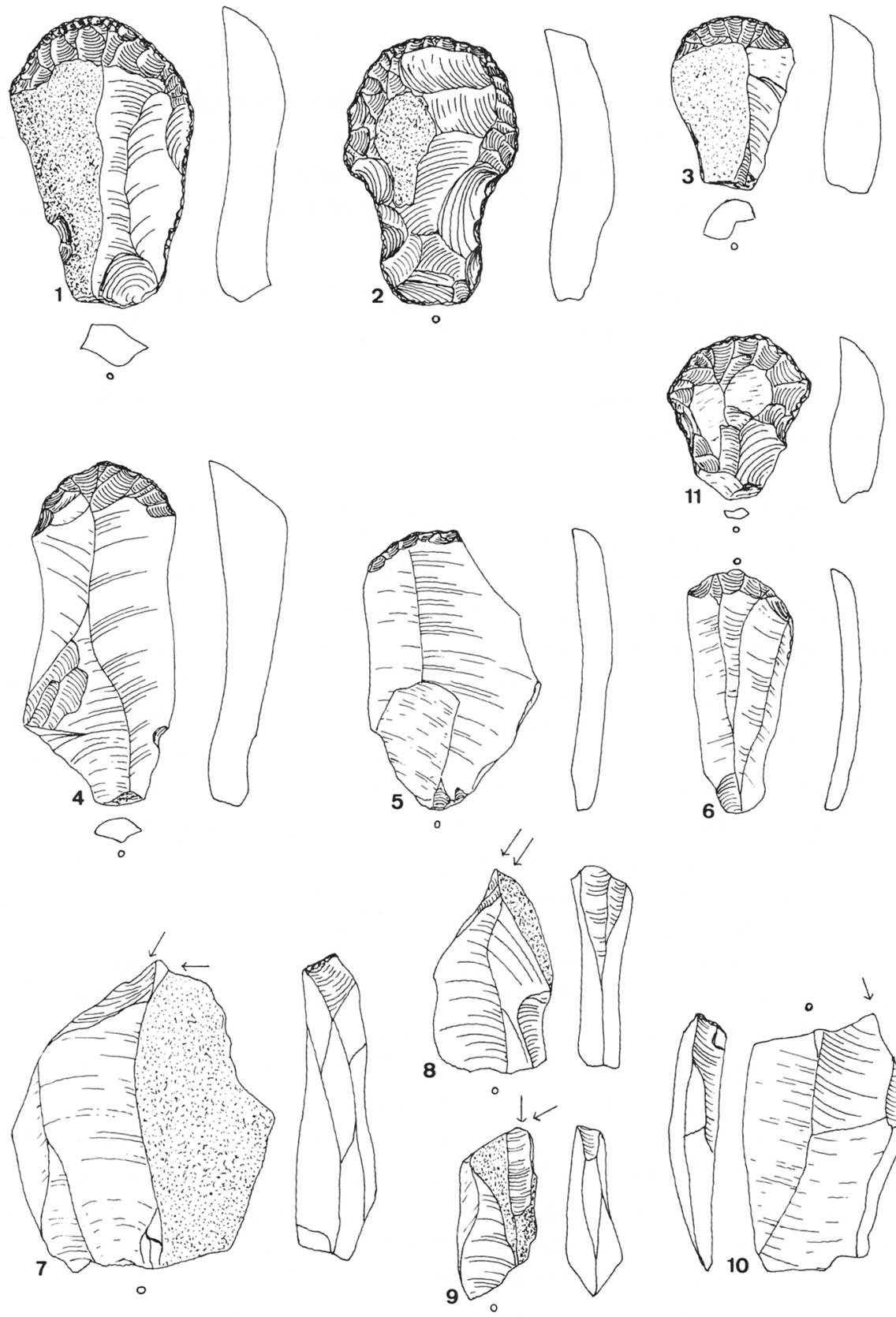

Fig. 13. Skrabere og stikler fra bopladsen Ramsgård II. 3:4.

Scrapers and burins from settlement Ramsgård II. 3:4. 
nr. 1 og 4), der begge er kendetegnet ved borthuggede slagfladerester og retoucherede længdekanter, finder i det øvrige senglaciale danske redskabsinventar sine nærmeste paralleller i bopladsmaterialet fra Jels I (20) og Løvenholm (21). Samme skrabertype kendes i et større antal fra Federmessergruppens bopladsfund i det nordtyske område (22).

De 5 stikler er fremstillet af grove uensartede flintskiver og består af 2 kantstikler, 2 tværstikler og 1 midtstikkel.

Ramsgård II, Bjergby sogn. VHM sag nr. 286/1986. Bopladsen, der udgør et ca. $20 \times 20 \mathrm{~m}$ stort areal, er beliggende ca. $30 \mathrm{~m}$ over DNN på fladt terræn (fig. 5).

I 1987 gennemførte Vendsyssel historiske Museum en prøvegravning på lokaliteten uden at finde senglacialt genstandsmateriale under pløjelagsdybde.

Bopladsens redskabsinventar (fig. 12-13) består af 9 skafttungespidser, 6 skiveskrabere, 1 flækkeskraber og 4 stikler. Desuden er der fundet 94 forarbejdede og uforarbejdede flækker og skiver, der med mere eller mindre sikkerhed kan medregnes til det senglaciale fundstof.

8 af skafttungespidserne (fig. 1-7 og 9) er bredbladede kraftige typer. De 4 hele skafttungespidser (fig. $12 \mathrm{nr} .1-4$ ) varierer i længde fra 5,2-7 cm og i bredde fra 1,9-2,9 cm. Skafttungerne er overvejende groft tilhuggede - dog skiller skafttungespidsen (fig. $12 \mathrm{nr}$. 8) sig ud fra de øvrige ved at være fremstillet af en mere spinkel flække, der kun har let markeret og retoucheret skafttunge. På skafttungerne (fig. 12 nr. 2 og 6), der iøvrigt har let tilspidset skafttunge, er slagfladeresten borthugget. Skafttungespidsen (fig. 12 nr. 4) har læderet od. Ensidet eller tosidet spidsretouche er foretaget på skafttungespidserne fig. $12 \mathrm{nr}$. 2, 3, 7 og 9. Skafttungespidserne fig. $12 \mathrm{nr} .7$ og 9, der foreligger som spids-fragmenter, er overbrudt lige over skafttungens overgang til bladet. Paralleller til samtlige skafttungespidser fra Ramsgård II kendes fra bopladslokaliteten Bromme.

De 6 skiveskrabere (fig. 13 nr. 1-5 og 11) varierer i form og størrelse. Skiveskraberen (fig. 13 nr. 1), der har ensidet retoucheret længdekant og skiveskraberen (fig. 13 nr. 2), der både har bred skafttunge og dobbelt længdekantretouche, findes i lignende eksemplarer fra Federmessergruppens bopladsfund fra Nordtyskland (22). Det samme gælder for den lille let snudeformede type skiveskraber med længdekantretouche (fig. 13 nr. 11), der ud over at optræde i Federmesserinventar også findes i redskabsinventaret fra Løvenholm (11). Skiveskrabere af typer som fig. 13 nr. 4 og 5 findes fra lokaliteterne Bromme (1), Langå I (15) og Bro (23). Skiveskraberne fig. 13 nr. 2 og 5 har stejlretoucherede ægforløb, - de øvrige skrabere har fladretoucherede ægforløb.

Bopladsens 4 stikler består af 2 kantstikler, 1 tværstikkel og 1 midtstikkel. Stiklerne er fremstillet af uensartede og uregelmæssige mindre skiver. 

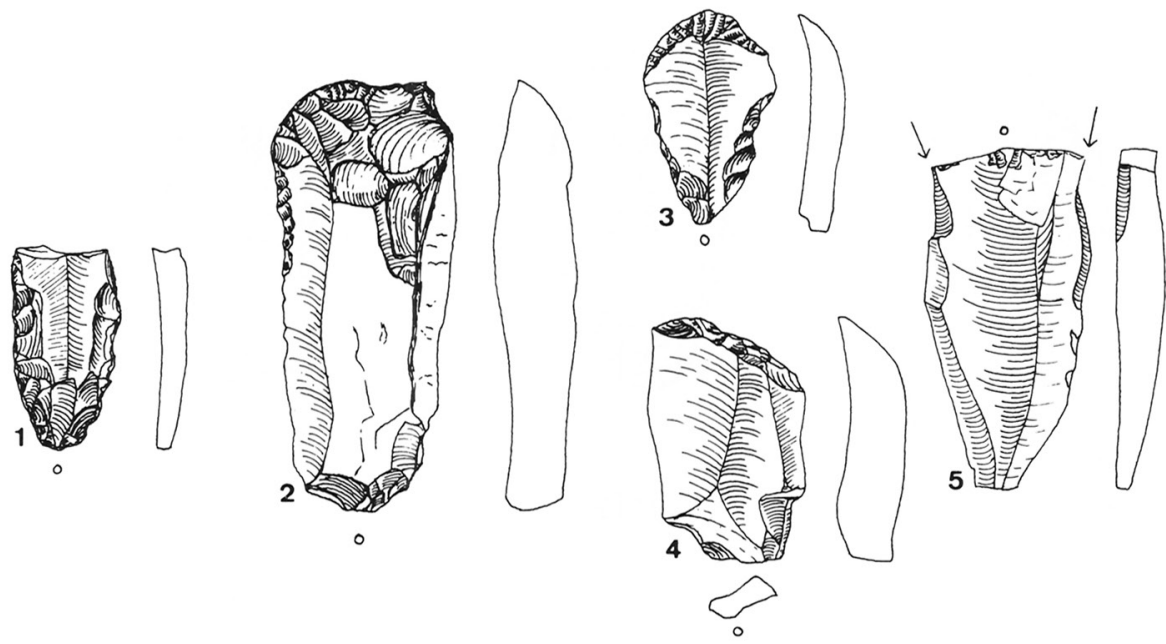

Fig. 14. Skafttungespids, skrabere og stikkel fra bopladsen Ramsgård III. 3:4.

Tanged point, scrapers and burin from settlement Ramsgård III. 3:4.

Ramsgård III, Bjergby sogn. VHM sag nr. 290/1986. Bopladsen, der udgør et ca. $15 \times 15 \mathrm{~m}$ stort areal, er beliggende ca. $29 \mathrm{~m}$ over DNN på let skrånende nordøstvendt terræn (fig. 5).

Redskabsmaterialet (fig. 14) består af 1 skafttungespids, 3 skiveskrabere og 1 stikkel. Desuden er der fundet 34 stykker forarbejdede og uforarbejdede flækker og skiver, der med større eller mindre sikkerhed kan medregnes til det senglaciale fundstof.

Skafttungespidsen (fig. $14 \mathrm{nr}$. 1) foreligger i form af en afbrudt skafttunge, hvor slagbule og slagfladerest er borthugget. Skafttungen er tilspidset og har let trimning på tværs af bugsiden.

Skiveskraberen (fig. 14 nr. 3) har fladretoucheret ægforløb, - de øvrige skrabere har stejlretoucherede ægforløb. Den lille kantretoucherede skiveskraber (fig. $14 \mathrm{nr}$. 3) finder sine nærmeste paralleller blandt Federmessergruppens skiveskrabere (22) og blandt skiveskraberne fra Løvenholm (21).

Ramsgård IV, Bjergby sogn. VHM sag nr. 292/1986. Bopladsen udgør et ca. $20 \times 20 \mathrm{~m}$ stort areal beliggende ca. $29 \mathrm{~m}$ over DNN på let mod sydøst skrånende terræn (fig. 5).

Redskabsmaterialet (fig. 15) består af 1 skafttungespids, 4 skiveskrabere, 1 flækkeskraber, 3 stikler og 2 skivebor. Desuden er der fundet 38 forarbejdede og uforarbejdede flækker og skiver, der med større eller mindre sikkerhed kan medregnes til det senglaciale fundstof.

Skafttungespidsen (fig. $15 \mathrm{nr}$. 1) er brækket lige over skafttungens overgang til bladet og foreligger som spidsfragment. 

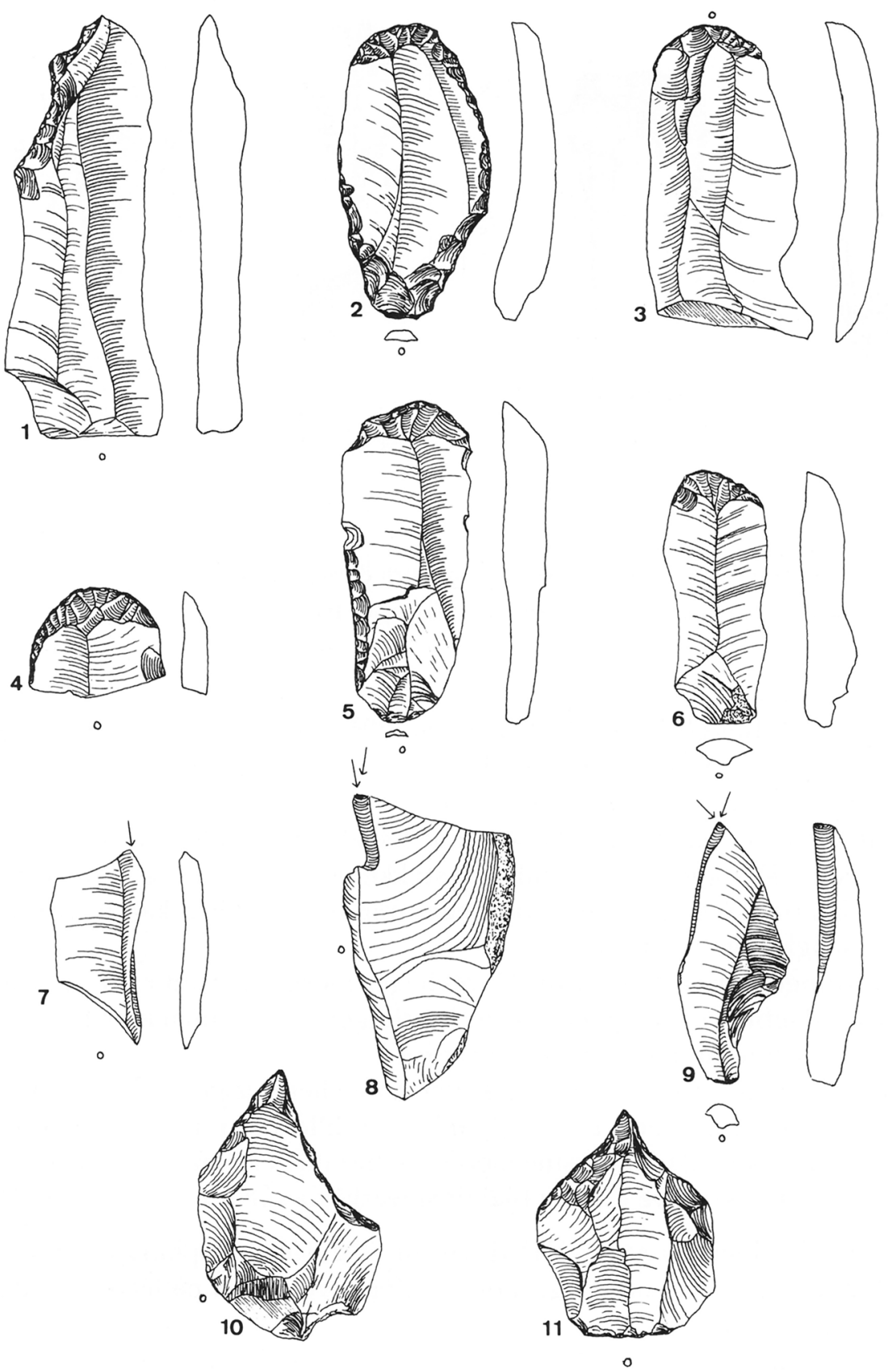

Fig. 15. Skafttungespids, skrabere, stikler og bor fra bopladsen Ramsgård IV. 3:4.

Tanged point, scrapers, burins and awls from settlement Ramsgård IV. 3:4. 
Skiveskraberen (fig. 15 nr. 2) med kantretouchering finder sine nærmeste paralleller i den nordtyske Federmessergruppe (22). De øvrige skiveskrabere og flækkeskraberen kendes i lignede eksemplarer fra »klassisk « Bromme-inventar. Skraberen (fig. 15 nr. 3) har stejlretoucheret ægforløb, de øvrige skrabere har fladretoucherede ægforløb.

Stiklerne (fig. 15 nr. 7-9), 2 kantstikler og 1 midtstikkel er fremstillet af uensartede uregelmæssige skiver.

Bopladsens to skivebor (fig. $15 \mathrm{nr} .10 \mathrm{og} 11$ ) har dobbeltsidet borspidsretouche og er fremstillet af små kraftige skiver.

Ramsgård V, Bjergby sogn. VHM sag nr. 453/1986. Bopladsen, der udgør et ca. $20 \times 20 \mathrm{~m}$ stort areal, er beliggende ca. $31 \mathrm{~m}$ over DNN på flad mark (fig. 5).

Redskabsinventaret består af 4 skafttungespidser, 1 flækkekniv, 3 skiveskrabere, 3 stikler og 1 skivebor. Desuden er der fundet 23 forarbejdede og uforarbejdede flækker og skiver, der med større eller mindre sikkerhed kan medregnes til det senglaciale fundstof.

De 4 skafttungespidser (fig. 16 nr. 1-4) er spinkle eksemplarer. De varierer i længde fra 4,1-6,2 cm og i bredde fra 1,9-2,2 cm. To af skafttungespidserne (fig. $16 \mathrm{nr} .1 \mathrm{og} 4$ ) har tilspidsede skafttunger. De to øvrige skafttungespidser (fig. 16 nr. 2-3) har bevaret en rest af slagfladen.

Flækkekniven (fig. 16 nr. 5), der er fremstillet af en bred »højrygget« flække, har kantretouchering ved »knivspidsen « i stykkets distalende.

Skiveskraberne (fig. 16 nr. 6-8) er fremstillet af kraftige og brede regelmæssige skiver. Skiveskraberen (fig. $16 \mathrm{nr}$. 7) har et let snudeformet ægforløb. Skiveskraberen (fig. 16 nr. 8) har ensidet kantretouche. Bopladsens 3 skrabere har stejlretoucherede ægforløb.

Stiklerne (fig. 16 nr. 9-11) er alle kantstikler. Stiklen (fig. 16 nr. 11) har stikkelslag udført på retoucheret kantforløb.

Skiveboret (fig. 16 nr. 12) er fremstillet af en lille kraftig skive. Boret har tosidet spidsretouche og kantretouche.

Redskabsmaterialet fra Ramsgård V kan som helhed henføres til Brommekulturen, - dog med flækkekniven og skiveboret (fig. $16 \mathrm{nr} .5 \mathrm{og} 12$ ) som afvigende elementer.

Ramsgård VI, Bjergby sogn. VHM sag nr. 159/1988. Bopladsen, der udgør et ca. $20 \times 20 \mathrm{~m}$ stort areal, er beliggende på flad mark ca. $31 \mathrm{~m}$ over DNN (fig. 5).

Redskabsmaterialet består af 1 skafttungespids og 2 skiveskrabere (fig. 17). Desuden er der fundet 4 forarbejdede og uforarbejdede flækker og skiver, der med større eller mindre sikkerhed kan medregnes til det senglaciale fundstof. 

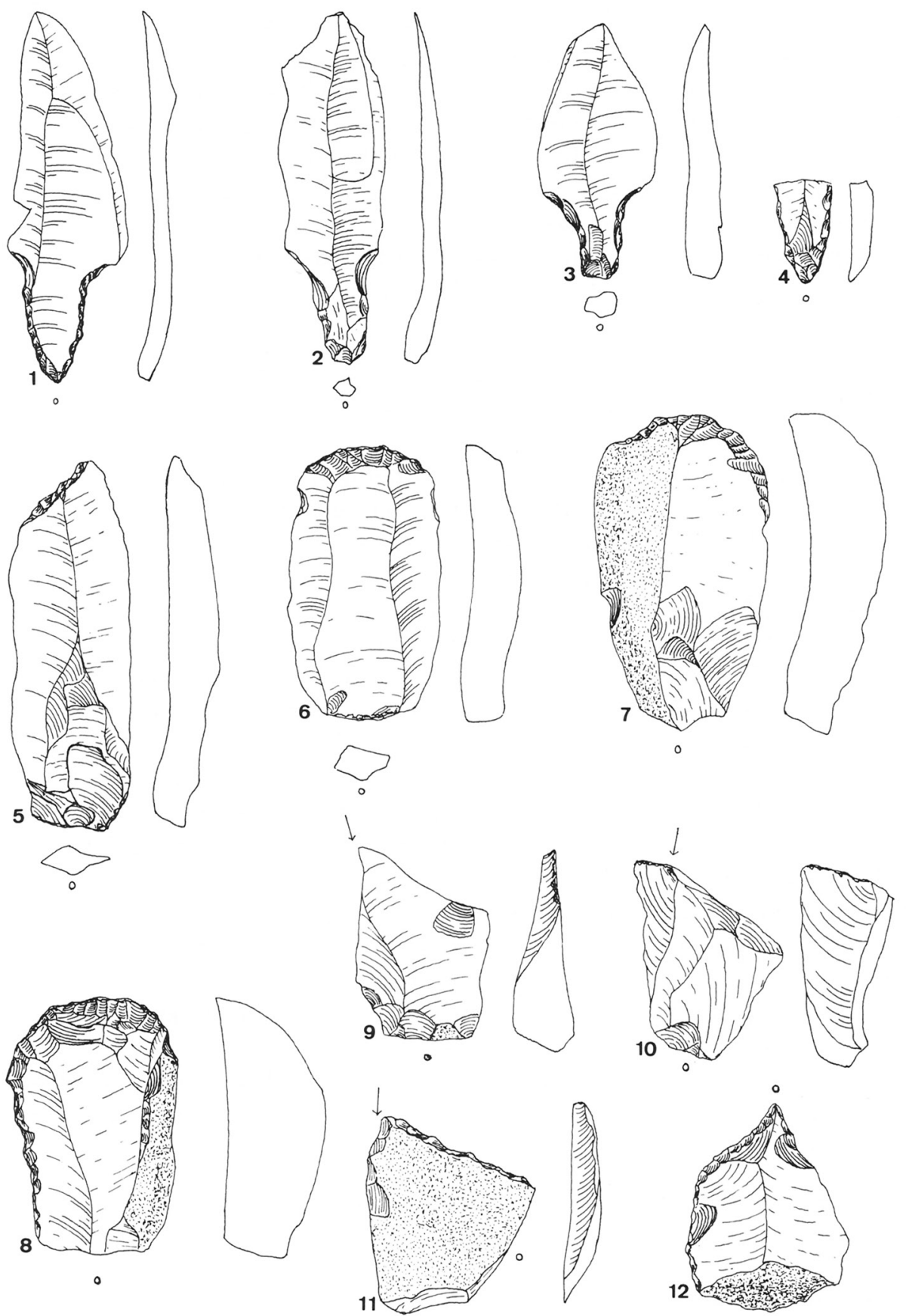

Fig. 16. Skafttungespidser, flækkekniv, skrabere, stikler og bor fra bopladsen Ramsgård V. 3:4. Tanged points, blade knife, scrapers, burins and awl from settlement Ramsgård V. 3:4. 


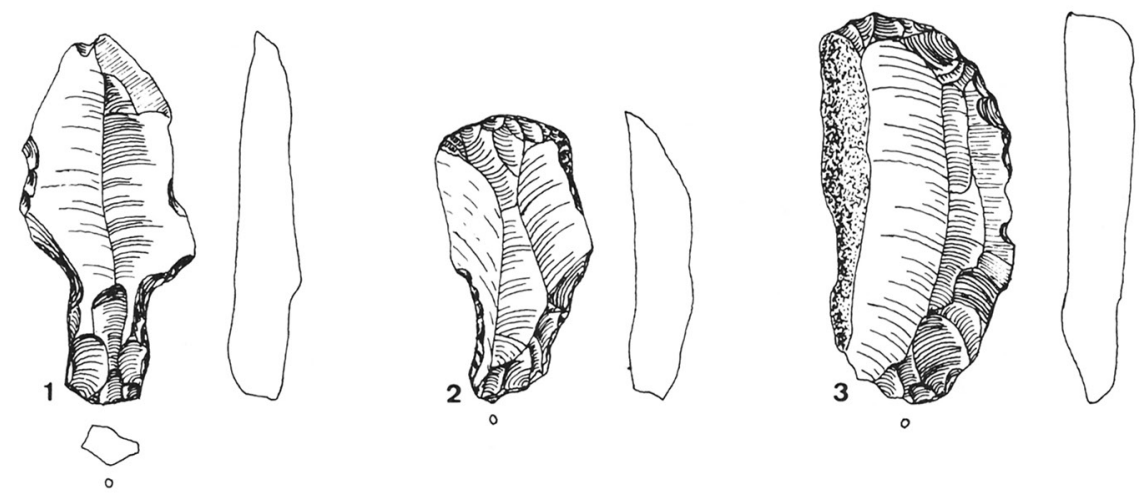

Fig. 17. Skafttungespids og skrabere fra bopladsen Ramsgård VI. 3:4.

Tanged point and scrapers from settlement Ramsgård VI. 3:4.

Skafttungespidsen (fig. $17 \mathrm{nr}$. 1), der er fremstillet af en kort kraftig flække, har groft tilhugget skafttunge samt en del af den oprindelige slagflade bevaret. Odden er stærkt beskadiget.

Skiveskraberen (fig. $17 \mathrm{nr}$. 2), der har tilhugget skafttunge og fladretoucheret ægforløb, kan være en genbrugt skafttungespids. Skiveskraberen (fig. $17 \mathrm{nr}$. 3), der er fremstillet af en kraftig skive, har "nedtrukket« og stejlretoucheret ægforløb langs den ene længdekant.

Skafttungespidsen og skiveskraberen (fig. $17 \mathrm{nr} .1$ og 3) kendes i lignende eksemplarer fra »klassisk « Brommeinventar. Skiveskraberen (fig. $17 \mathrm{nr}$. 2), der snarere burde benævnes skafttungeskraber, kendes i lignende eksemplarer fra Løvenholm (24).

Ramsgård VII, Bjergby sogn. VHM sag nr. 160/1988. Bopladsen, der udgør et ca. $15 \times 15 \mathrm{~m}$ stort areal, er beliggende på flad mark ca. $31 \mathrm{~m}$ over DNN, (fig. 5).

Redskabsinventaret består af en enkelt skafttungespids (fig. 18). Desuden er der fundet 2 uforarbejdede skiver der med større eller mindre sikkerhed kan medregnes som senglaciale genstande.

Skafttungespidsen, der har tilspidset skafttunge og uretoucheret od, ligger typemæssigt tæt op ad skafttungespidsen (fig. 16 nr. 1), og må kategoriseres som en skafttungespids af Brommetype.

Ramsgård VIII, Bjergby sogn. VHM sag nr. 361/1988. Bopladsen, der udgør et ca. $15 \times 15 \mathrm{~m}$ stort areal, er beliggende på flad mark ca. $31 \mathrm{~m}$ over DNN, (fig. 5).

Redskabsinventaret (fig. 19) består af 3 skafttungespidser og 1 skiveskraber. Desuden er der fundet 3 uforarbejdede flækker, der med større eller mindre sikkerhed kan medregnes til det senglaciale fundstof. 


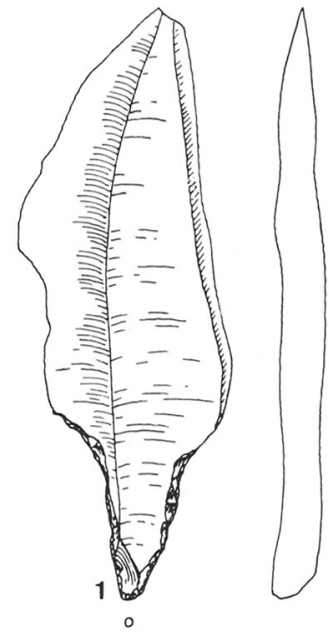

Fig. 18. Skafttungespids fra bopladsen Ramsgård VII. $3: 4$.

Tanged point from settlement Ramsgård VII. 3:4.
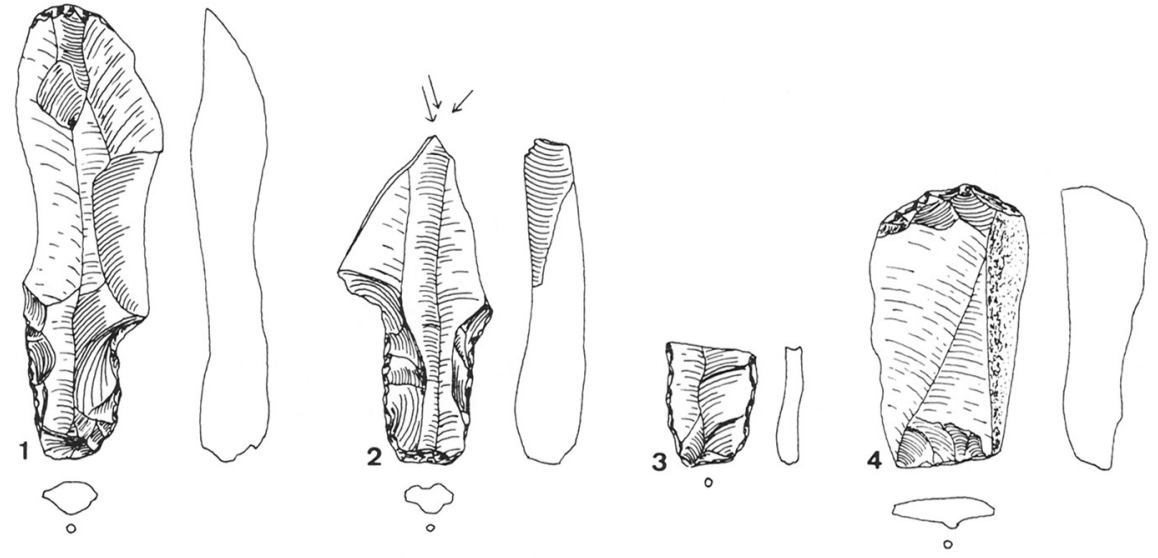

Fig. 19. Skafttungespidser og skraber fra bopladsen Ramsgård VIII. 3:4.

Tanged points and scraper from settlement Ramsgård VIII. 3:4.
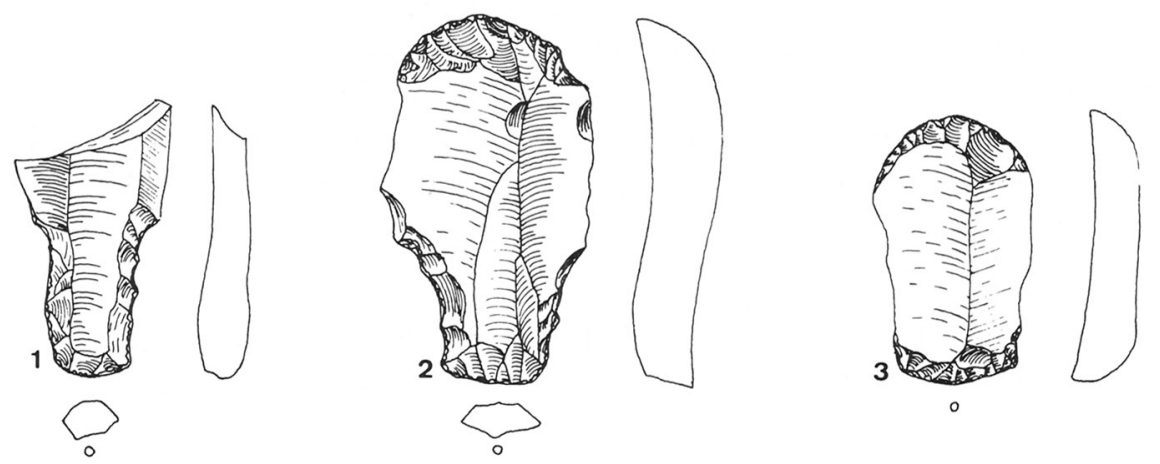

Fig. 20. Skafttungespids og skrabere fra bopladsen Ramsgård IX. 3:4.

Tanged point and scrapers from settlement Ramsgård IX. 3:4. 
De to skafttungespidser (fig. $19 \mathrm{nr} .1$ og 2) er fremstillet af forholdsvis korte men kraftige flækker. Begge har dele af den oprindelige slagflade bevaret. Skafttungespidsen (fig. $19 \mathrm{nr}$. 1) er efter beskadigelse af odden genanvendt som skraber. Skafttungespidsen (fig. 19 nr. 2), er, sandsynligvis efter en beskadigelse af odden, genanvendt som stikkel.

Skiveskraberen (fig. 19 nr. 4) har stejlretoucheret ægforløb.

Skafttungespidserne kan kategoriseres som skafttungespidser af Brommetype.

Ramsgård IX, Bjergby sogn. VHM sag nr. 362/1988. Bopladsen, der udgør et ca. $15 \times 15 \mathrm{~m}$ stort areal, er beliggende på flad mark ca. $31 \mathrm{~m}$ over DNN (fig. 5).

Redskabsmaterialet (fig. 20) består af 1 skafttungespids og 2 skiveskrabere. Desuden er der fundet 3 uforarbejdede skiver, der med større eller mindre sikkerhed kan henføres til det senglaciale fundstof.

Skafttungespidsen (fig. $20 \mathrm{nr}$. 1), der foreligger som skafttungefragment, har kort og kraftig skafttunge med slagfladerest bevaret.

Skiveskraberen (fig. $20 \mathrm{nr}$. 2), der er fremstillet af en kraftig og bred skive, har rundbuet og fladretoucheret ægforløb samt en bred og kraftig skafttunge. Paralleller til denne skrabertype kendes fra Federmessergruppens bopladser i Nordtyskland (22). Skiveskraberen med dobbeltæg (fig. $20 \mathrm{nr}$. 3), der henholdsvis har stejlretoucheret og fladretoucheret ægforløb i hver sin ende, kendes i lignende eksemplarer fra Bro (18) og Bromme (25), men er også til stede i den nordtyske Federmessergruppes redskabsinventar.

\section{Hollendskær - genstandsmaterialet, generelle træk og kronologisk placering}

Hele det senglaciale bopladsmateriale fra Hollendskær består af rekognosceringsfund. Genstandsmængden fra bopladserne øges år for år, og de enkelte bopladsers redskabssammensætning veksler i takt med de gentagne rekognosceringer. Det aktuelle genstandsbillede af de enkelte bopladser er derfor langt fra komplet. Samtidig er der stor fare for, at forskellige bopladsfaser er sammenblandet, eller at enkelte yngre genstande er iblandet det senglaciale genstandsmateriale, - sandsynligvis er dette sket i større eller mindre omfang. På det grundlag vil det enkelte bopladsinventars karakteristika ikke kunne tillægges den store »sandhedsværdi«.

Under forudsætning af at bopladserne alle stammer fra samme brede tidshorisont, behandles redskabsinventaret fra Hollendskær i det følgende under eet, og nogle generelle tendenser i redskabsinventaret udledes. 
Skafttungespidser. Råemnerne til aktivitetsområdets 41 skafttungespidser er overvejende uensartede brede og "højryggede" flækker med "naturlig" spids distalende. Flækkerne er fremstillet ved hårdt direkte slag. Skafttungespidserne, der veksler meget i form og størrelse, varierer i længde fra 4,6$10,1 \mathrm{~cm}$ og i bredde fra $1,5-3,5 \mathrm{~cm}$. Hovedparten af skafttungespidserne har groft tilhuggede skafttunger med tilnærmelsesvis parallelt løbende sidekanter og dele af den oprindelige slagflade bevaret. Skafttungerne er i alle tilfælde tilhugget fra bugsiden i råemnets proximalende. Tilspidsede skafttunger findes på 6 skafttungespidser. Skafttungespidsernes odde er i 7 tilfælde »justeret « ved hjælp af en- eller tosidet spidsretouche. Hovedparten af skafttungespidserne foreligger som beskadigede eksemplarer, enten med beskadigede odde eller som spids- eller skafttungefragmenter.

Skrabere. Råemnet til de 37 skrabere er overvejende små uensartede grove skiver. Skraberne kan groft opdeles i 4 grupper: simple skrabere, 17 stk. Skrabere med kantretouche og/eller skafttunge, 13 stk. Skrabere med snude eller skulder, 6 stk. Dobbeltskrabere, 1 stk.

Skraberne, der er domineret af simple skive- eller flækkeskrabere, gør sig specielt bemærket ved det høje antal skrabere med kantretouche og/eller skafttunge.

Skrabernes ægforløb er fremstillet ved stejlretouchering, eller som det mest hyppige, ved fladretouchering bestående af lange smalle afspaltninger afsluttet med fin ægtrimning.

Skrabernes ægforløb er, på nær en enkelt undtagelse, placeret i råemnets distalende.

Stikler. Aktivitetsområdets 17 stikler er overvejende fremstillet af uensartede skiver. Stiklerne fordeler sig med 11 kantstikler, 3 tværstikler og 3 midtstikler.

Flakkeknive. Flækkeknive forekommer ved Hollendskær i 3 tilfælde (fig. 7 nr. 4 , fig. 9 nr. 4 og fig. 16 nr. 5).

Flækkeknivene er fremstillet af lange ensartede kraftige og brede flækker med »naturlig« spids distalende. Flækkerne er frembragt ved hårdt direkte slag.

De to flækkeknive (fig. 7 nr. 4 og fig. 9 nr. 4) har ensidet længdekantretouche med let afsat retouchering ved spidsen. Flækkekniven (fig. 16 nr. 5) har kun kantretouchering omkring spidsen.

Bor. Bor findes ved Hollendskær i 3 tilfælde (fig. $15 \mathrm{nr}$. $10 \mathrm{og} 11$ samt fig. 16 nr. 12). De tre bor, der alle er lavet af små kraftige skiver, har tosidet borspidsretouche foretaget fra samme side af råemnet.

Tabellen (fig. 21) over fundlokaliteternes redskabsfordeling, viser en klar dominans af skafttungespidser og skrabere indenfor aktivitetsområdet. 


\begin{tabular}{|c|c|c|c|c|c|}
\hline & 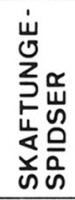 & 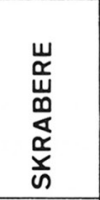 & $\frac{\stackrel{\alpha}{u}}{\stackrel{\vec{\gamma}}{E}}$ & 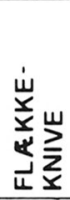 & $\underset{\infty}{\stackrel{\Upsilon}{0}}$ \\
\hline V. I & 5 & $1(2)$ & (1) & & \\
\hline V. II & 1 & 2 & & 1 & \\
\hline V. III & 1 & 4 & 1 & & \\
\hline V. IV & 3 & 1 & & 1 & \\
\hline R. I & 10 & $6(7)$ & 5 & & \\
\hline R. II & 9 & 7 & 4 & & \\
\hline R. III & 1 & 3 & 1 & & \\
\hline R. IV & 1 & 5 & 3 & & 2 \\
\hline R. V & 4 & 3 & 3 & 1 & 1 \\
\hline R. VI & 1 & 2 & & & \\
\hline R. VII & 1 & & & & \\
\hline R. VIII & 3 & $1(2)$ & (1) & & \\
\hline R. IX & 1 & 2 & & & \\
\hline TOTAL & 41 & $37(40)$ & $17(19)$ & 3 & 3 \\
\hline
\end{tabular}

Fig. 21. Redskabsstatistik for Varbro (V) I-IV og Ramsgård (R) I-IX. »Genbrugte « redskaber figurerer i tabellen som den oprindelige redskabstype. I parentes er angivet antal redskabstyper, når de genbrugte redskaber optræder både som den oprindelige og som den nye redskabstype.

Implement statistics for Varbro (V) I-IV
and Ramsgård (R) I-IX. "Re-used " im-
plements are shown in the table under the
original implement type. The number of
implement types when the re-used imple-
ments appear both as the original and the
new implement type is given in brackets.

Den procentvise fordeling mellem de tre hyppigst forekommende redskabstyper er således: skafttungespidser $43 \%$, skrabere $39 \%$ og stikler $18 \%$. Forholdstalsmæssigt er fordelingen mellem de tre redskabstyper 2:2:1.

En kronologisk placering af Hollendskærbopladserne i det senglaciale tidsforløb er, på baggrund af de aktuelt tilgængelige bopladsdata, kun mulig ad typologisk vej.

Blandt de 41 noget forskelligartede skafttungespidser, der alle kan henføres til Brommekulturen, findes eksemplarer der muligvis kan repræsentere henholdsvis ældre og yngre faser indenfor Brommekulturen.

De 37 skrabere domineres af 17 simple skrabere, der er almindeligt forekommende på »klassiske« Bromme-lokaliteter. Hertil kommer 6 skrabere med skulder eller snude - skrabertyper der ligeledes kendes fra Bromme-inventar. 13 overvejende små skrabere med kantretouche og/eller skafttunge skiller sig markant ud fra de øvrige skrabertyper. Fuldstændig identiske eksemplarer kendes fra den nordtyske Federmessergruppes (22) bopladser, fra Løvenholm, der sandsynligvis repræsenterer en tidlig fase af Brommekulturen (31), og fra bopladsen Jels I, der placeres sent i Hamburgkulturens tidsforløb (32).

Stikler er vanskeligt anvendelige som kronologiske ledetyper og lades i denne forbindelse ude af betragtning.

De »rygretoucherede« knive, der fra Hollendskær foreligger i 3 eksemplarer, er en redskabstype der optræder i forskellige varianter i Federmessergruppens redskabsinventar.

Tre skivebor er på typologisk noget usikker baggrund medregnet i Hollendskærs senglaciale fundstof, og de vil derfor ikke indgå i dateringsmæssige overvejelser. 
Bopladsfundene fra Hollendskær kan i sin helhed placeres indenfor Brommekulturen. Skraberne med skafttunge og/eller kantretouche, såkaldte Wehlener-skrabere, som også kendes fra bopladsen Jels I, der indtager en tidsmæssig sen placering indenfor Hamburgkulturen, viser, at dele af Hollendskærs redskabsinventar sandsynligvis skal placeres i en tidlig fase af Brommekulturen. Sammenholdes dette med det store indhold af »klassisk « Bromme-inventar, tyder meget på, at lokaliteten Hollendskær har været anvendt over en lang periode indenfor Brommekulturens måske over 1.000 årige levetid.

De nære typologiske ligheder mellem redskabsinventar fra henholdsvis Hollendskær og bopladser fra Federmessergruppen i Nordtyskland betyder, at senglacialtidens jægere i Vendsyssel øjensynlig på det tidspunkt var influeret af og sandsynligvis havde direkte kontakt med jægergrupper fra det sydlige Danmark og Nordtyskland.

\section{Hollendskær - bosættelseskarakteristik}

Med baggrund i bopladsernes redskabssammensætning og beliggenhed er det muligt at drage nogle forsigtige slutninger omkring bosættelseskarakteren ved Hollendskær.

Skafttungespidsernes, skrabernes og stiklernes store antal set i forhold til bopladsernes sparsomme indhold af flintaffald tyder, sammenholdt med bopladsernes ringe størrelser, på, at bosættelserne omkring Hollendskær ikke har været af permanent karakter. Snarere er der tale om kortere måske sæsonvise ophold på stedet, hvor flintaffaldet og det varierede redskabsinventar viser, at en række almindelige bopladsaktiviteter også har fundet sted.

De mange skafttungespidser peger på, at jagt har været det overordnede formål med bosættelserne på netop Hollendskærlokaliteten. Tilstedeværelsen af skrabere, stikler, knive og bor sandsynliggør, at partering og forarbejdning af de nedlagte byttedyr har fundet sted på bopladserne.

Under jagten brækkede skafttungespidserne ofte i byttedyrene (26), og fundet af de mange beskadigede skafttungespidser, i form af skafttunge- og spidsfragmenter samt skafttungespidser med beskadigede odde, forstærker billedet af bopladserne som basislejre for jagtaktiviteter. De defekte pile er hjembragt til bopladserne, hvor skafttungefragmenterne er afmonteret. Spidsfragmenterne har sandsynligvis siddet i nedlagte byttedyr og først fremkommet ved parteringen af dyrene.

Bopladsernes beliggenhed ved bredden af en mindre ferskvandssø og tæt ved en ådal gør det sandsynligt, at indsamling, fiskeri samt fugle- og småvildtjagt kan have spillet en betydelig rolle ved siden af storvildtjagten i de senglaciale jægeres økonomi. 


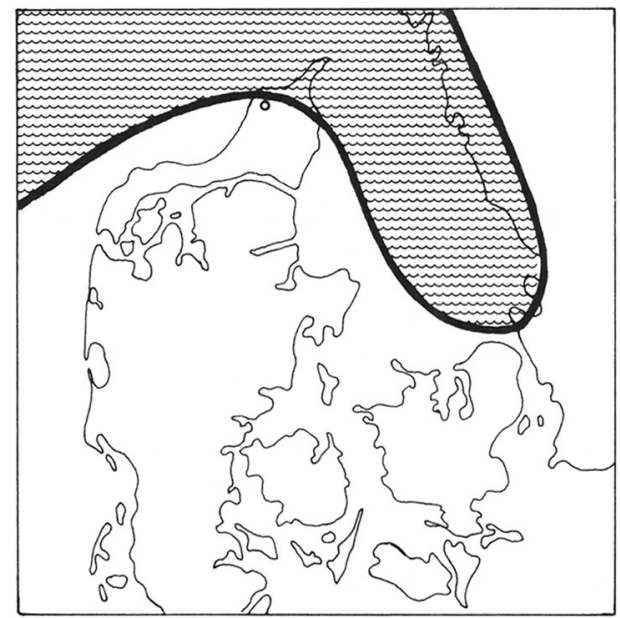

Fig. 22. Forholdet mellem land og hav ca. 9.000 f.Kr. (29). Cirklen angiver Hollendskærs beliggenhed.

Relationship between land and sea about 9,000 B.C. (29). The circle denotes the location of Hollendskær.

Måske har bopladserne samtidig ligget tæt op ad et vigtigt overgangssted i ådalen, hvor større jagtdyr, som f.eks. rensdyret, passerede på deres sæsonvise træk gennem området.

De forholdsvis små bopladsstørrelser antyder, at det er små sociale enheder, måske familier eller små familiegrupper, der har benyttet lokaliteten ved Hollendskær. Disse familier kan, i lighed med de oprindelige samer i Nordskandinavien, have bygget deres livsgrundlag op omkring rensdyret, som var leveringsdygtig i de fleste livsfornødenheder. Med det udgangspunkt kan Hollendskær-bopladserne tolkes som jagtstationer eller rastepladser, der indgik i et større system af lignende lokaliteter, der benyttedes af senglacialtidens jægere på deres sæsonvise vandringer i kølvandet på rensdyrflokkene. Sandsynligvis har Brommekulturens jægere, som Ahrensburgkulturens, haft lette teltkonstruktioner (27), der let kunne transporteres.

Hollendskær-bopladserne er således øjensynlig fundophobninger dannet via gentagne kortvarige sommerophold på lokaliteten over en lang årrække.

Spredningsbilledet for det senglaciale fundstof i Vendsyssel (fig. 1) viser, at senglacialtidens jægere var særdeles mobile og magtede at bevæge sig over store områder. Det viser også, at Vendsyssel i Allerødtid var eet sammenhængende og farbart i landområde. Nye geologiske undersøgelsesresultater (28) viser da også, at fastlandstidens Danmark er en realitet allerede i slutningen af Allerødtid, og at det nordvesteuropæiske lavlands nordligste kystlinier på det tidspunkt forløb kun ca. 7 km nord for jagtstationerne ved Hollendskær. Hollendskærbopladserne er således det nordvesteuropæiske lavlands nordligst beliggende bopladser fra Allerødtid (fig. 22). 
NOTER

1) Mathiassen, Th.: En senglacial Boplads ved Bromme. Aarb. for nord. Oldk. og Hist. 1946, s. 121 ff.

2) Den øgede genstandstilvækst indenfor det sidste årti skyldes først og fremmest ihærdig og målrettet rekognoscering foretaget af amatørarkæologerne Otto E. Kristensen, Hirtshals og Finn G. Frandsen, Tornby, i samarbejde med VHM.

3) Vendsyssel bruges i artiklen som betegnelse for Vendsyssel historiske Museums arbejdsområde, der består af: Børglum h., Dronninglund h., Horns h. Hvetbo h. (minus Gøl og Vedsted sogne), Læsø h. og Vennebjerg h.

4) Jessen, A. og Nordmann, V.: Ferskvandslagene ved Nørre Lyngby, 1915, s. 52-56.

5) Materialebestemmelsen er foretaget i 1975 af Ulrik Møhl, Zoologisk Museum i København. Usikkerheden i materialebestemmelsen skyldes, at slagvåbnets overfladestruktur er ødelagt af vandrulning.

6) Andersen, S. H.: A survey of the late Palaeolitic of Denmark and southern Sweden. De la Loire à l'Oder. Les civilisations du Paleólithique final dans le nord-ouest europeén. BAR International Series 444 (i), 1988.

7) Bopladserne fra Hollendskær er tidligere kort omtalt i Vendsyssel Årbog 1988, s. 141-149: Nilsson, T., Kristensen, O. E. og Frandsen, F. G. Jagtpladser fra senistidens Vendsyssel.

8) Bopladsens redskaber er fundet og venligst udlånt af lærer Jørgen Klenø, Hjørring.

9) Fischer, A. og Nielsen, F. O. S.: Senistidens bopladser ved Bromme. En genbearbejdning af Westerbyś og Mathiassenś fund. Aarb. for nord. Oldk. og Hist. 1986, s. 29.

10) Holm, J. og Rieck, F.: Die Hamburger Kultur in Dänemark. Archäologisches Korrespondenzblatt 17, 1987, s. 157.

11) Madsen, B.: New Evidence of late Palaeolitic Settlement in East Jutland. Journal of Danish Archaeology, vol. 2, 1983, s. 18.

12) Andersen, S. H.: Bro, en senglacial boplads på Fyn. KUML 1972, s. 7-60.

13) Andersen, S. H.: 1972, s. 30.

14) Fischer, A. og Nielsen, F. O. S.: 1986, s. 23.

15) Madsen, B.: 1983, s. 23.

16) Schwabedissen, Hermann: Die Federmesser-Gruppen des nordwesteuropäischen Flachlandes, 1954.

17) Fischer, A. og Nielsen, F. O.S.: 1986, s. 24.

18) Andersen, S. H.: 1972, s. 31.

19) Fischer, A. og Nielsen, F. O.S.: 1986, s. 26.

20) Holm, J. og Rieck, F.: 1987, s. 157 Abb. 6 nr. 3-5.

21) Madsen, B.: 1983, s. 18 fig. 6 nr. L, N og O.

22) Schwabedissen, H.: 1954. Lokaliteterne Nettelhorst og Wehlen, Tafel 41 og 57.

23) Andersen, S.H.: 1972, s. 29.

24) Madsen, B.: 1983, s. 18, fig. 6 nr. L, M og N.

25) Mathiassen, T.: 1946, s. 145.

26) Fischer, A., Hansen, P. V. og Rasmussen, P.: Macro and Micro Wear Traces on Lithic Projectile Points. Journal of Danish Archaeology vol. 3, 1984, s. 29-30.

27) Tromnau, G.: Rentierjäger der Späteiszeit in Norddeutschland. 1976.

28) Petersen, K. S.: The Late Quaternary History of Denmark. Journal of Danish Archaeology vol. 4, 1985, s. 10.

29) Kortet er udtegnet på grundlag af kortet i: Petersen, K. S.: 1985, s. 10.

30) Fischer, A. og Nielsen, F. O. S.: 1986, s. 30.

31) Madsen, B.: 1983, s. 29

32) Holm, J. og Rieck, f.: 1987, s. 164. 
Late Glacial settlement in Vendsyssel

The number of Late Glacial finds in Vendsyssel have increased dramatically during the last decade, and the first settlements of this era have been recorded. The present article surveys the Late Glacial material from Vendsyssel (3), as of 1989.

The total find material consists of 12 single finds and 15 settlement finds. In the presentation, which consists entirely of surface finds, the main emphasis has been placed on an area of major activity, Hollendskær (7).

The single finds (figs. 1-3) comprise 10 tanged points and 2 striking weapons of reindeer antler. The tanged points can all be assigned to the Bromme culture ( 1 and 9$)$, but the two strikers, which may be typologically attributed to the Ahrensburg culture's (27) group of strikers, are difficult to place chronologically, as such weapons have yet to be found in Denmark in datable context.

The settlements, which are all in an elevated position on moraine or Yoldia tracts close to wet areas, comprise 2 isolated settlements, Højvælde and Trudslev (fig. 1:2 \& 6), and 13 settlements within a singe activity area (Hollendskær (fig. 1:1 and fig. 5). The two isolated settlelements, Højvælde (fig. 4:4-6) and Trudslev (fig. 4: 1-3), can both be referred to the Bromme culture. The Hollendskær settlements are scattered over an area measuring c. 200 $\times 700 \mathrm{~m}$ (fig. 5), along the west and south banks of a large tract of meadowland, which in prehistoric times was a freshwater lake covering about $0.5 \mathrm{sq} . \mathrm{km}$. The lake had outlet via a narrow cleft to a large river valley, and the settlements lie on the north and south sides of this cleft.

The artefact material from the settlements of the activity area (figs. 6-20) - 41 tanged points, 37 scrapers, 17 burins, 3 blade knives and 3 borers - can be generally referred to the Bromme culture, but a few typological elements point to an early date. The $»$ keel retouched " blade knives (figs. 7:4, 9:4 and 16:5) have clear parallels in the inventory of the north German Federmesser group (16), and the scrapers with surface-retouched edges and long-edge retouch feature both in the Federmesser inventory and in Danish settlement inventory placed within the Hamburg culture (10) or the early part of the Bromme culture (11).

The Hollendskær settlements are interpreted as hunting stations, occupied seasonally by small social groups for a span of years.

They are the northernmost settlements of the northwest European plains from the Allerød period (fig. 22).

Torben Nilsson

Vendsyssel historiske Museum, Hjørring

Tegning: Forfatteren

Oversattelse: Peter Crabb 
